\title{
Impact of Strength and Proximity of Receiving AC Systems on Cascaded LCC-MMC Hybrid HVDC System
}

\author{
Yongjie He, Wang Xiang, Member, IEEE, Binye Ni, Xiaojun Lu, Member, IEEE, Jinyu Wen, Member, \\ IEEE
}

\begin{abstract}
The cascaded hybrid LCC-MMC inverter is considered as a feasible option to mitigate the commutation failure problem of conventional LCC-HVDC while maintaining bulk power transmission capability. However, the coupling between different types of converters may result in instability when the inverter integrates with weak AC systems. This paper establishes a small-signal model of the cascaded LCC-MMC inverter based hybrid HVDC system and validates the model against PSCAD/EMTDC. Through eigenvalue analysis, the impact of the strength and proximity of receiving $\mathrm{AC}$ systems on the smallsignal stability is investigated, and the stable zone of the strength of receiving $\mathrm{AC}$ systems is identified. Besides, a supplementary coupling mitigation control is proposed to tackle the instability problem under weak AC systems integration. Both analytical results and time-domain simulations demonstrate the validity of the supplementary control.
\end{abstract}

Index Terms- Cascaded hybrid HVDC, line commutated converter, modular multilevel converter, renewable energy, smallsignal stability.

\section{NOMENCLATURE}

Variables:

$R_{s i}, L_{s i}$

resistance and inductance of AC system $i$ $(i=1,2,3)$

$R_{\text {tie }}, L_{\text {tie }}$ resistance and inductance of tie line

$L_{T 1}, L_{T 2}, L_{T 3}$ leakage inductance of transformers of LCC inverter, MMC and LCC rectifier

$L_{d c}$ DC current-limiting inductance

$R_{\text {line }}, L_{\text {line }}, C_{\text {line }}$ resistance, inductance and capacitance of DC line

$v_{s i}, i_{s i}$ voltage and current of AC system $i(i=1$, $2,3)$

$v_{p c c i}$

$i_{\text {tie }}$

$v_{c 1}, i_{c 1}$

$v_{c 2}, i_{c 2}$

$v_{c 3}, i_{c 3}$

$i_{f r}, i_{f i}$

$v_{c h p}^{i}, v_{c 1}^{i}, v_{c 2}^{i}$

$i_{l h p}^{i}, i_{l 1}^{i}, i_{l 2}^{i}$

$v_{c h p}^{r}, v_{c 1}^{r}, v_{c 2}^{r}$

$i_{\text {lhp }}^{r}, i_{l 1}^{r}, i_{l 2}^{r}$

voltage of $\mathrm{PCC}_{i}(i=1,2,3)$

current on tie line

$\mathrm{AC}$ voltage and current of LCC inverter

$\mathrm{AC}$ voltage and current of $\mathrm{MMC}$

$\mathrm{AC}$ voltage and current of $\mathrm{LCC}$ rectifier currents injected into filters at PCCs capacitor voltages of filter at $\mathrm{PCC}_{1}$ inductor currents of filter at $\mathrm{PCC}_{1}$ capacitor voltages of filter at $\mathrm{PCC}_{3}$ inductor currents of filter at $\mathrm{PCC}_{3}$

This work is sponsored by the National Natural Science Foundation of China (51907068) (Corresponding author: Wang Xiang).

Y. He, B. Ni and J. Wen are with the State Key Laboratory of Advanced Electromagnetic Engineering and Technology, Huazhong University of Science and Technology, Wuhan 430074, China (e-mail: yjhe1002@foxmail.com; nibinye@foxmail.com; jinyu.wen@hust.edu.cn).

W. Xiang is with the Department of Electronic and Electrical Engineering, University of Strathclyde, Glasgow, G1 1XW, UK (email: xiangwang1003@foxmail.com).

$\mathrm{X}$. Lu is with Changjiang Institue of Survey, Planning, Design and Research Co. Ltd., Wuhan 430015, China (e-mail: luxiaojun1212@foxmail.com).

$v_{d c}^{L C C i}, v_{d c}^{M M C}, v_{d c}^{L C C r}$
$v_{\text {line } 1}, v_{\text {line } 2}$
$i_{\text {line }}$
$i_{d c 1}, i_{d c 2}$
$\omega_{0}$
$\omega, \theta_{p l l}$
$\beta_{\text {iord }}, \beta_{i}$
$\alpha_{\text {rord }}, \alpha_{r}$
$m, m_{2}$

Subscripts:

$x, y$

$x_{2}, y_{2}$

$d, q$

$d_{2}, q_{2}$

$m, r e f$

DC voltages of LCC inverter, MMC and LCC rectifier

terminal DC voltages of DC line

DC current on DC line

DC currents of rectifier-side and inverterside

rated angular frequency of AC system tracked angular frequency and output Phase angle of PLL

firing-advance angle order and actual firing-advance angle for LCC inverter firing-delay angle order and actual firingdelay angle for LCC rectifier fundamental-frequency and doublefrequency modulation indices

common rotating frame components double-frequency common rotating frame components

local rotating frame components double-frequency local rotating frame components measured and reference values

\section{INTRODUCTION}

High voltage direct current (HVDC) transmission technology is widely applied in renewable energy integration, asynchronous power grid interconnection and large-capacity power transmission over long distances [1][2]. Due to the advantages of low cost and bulk power transmission capability, the line commutated converter-based high voltage direct current (LCC-HVDC) is acknowledged to be one of the most mature solutions. In the past decades, more than 100 LCC-HVDC projects have been commissioned world widely [3]. However, with the increasing penetration of large-scale renewable energy, two or more LCC-HVDC links are fed into a regional power grid, resulting in a multi-infeed HVDC system. The LCC inverter is vulnerable to the commutation failure problem, which may lead to a continuous commutation failure of the multi-infeed HVDC system during AC grid faults, putting a severe threat to the safe and stable operation of the receiving AC grid [4].

To address this challenge, the modular multilevel converter (MMC) with self-commutation capability is adopted at the inverter-side [5][6]. Therefore, hybrid LCC-MMC HVDC systems combining the merits of both LCC and MMC are developed rapidly [7]. The hybrid HVDC systems can be classified into three types: (i) The pole-pole hybrid HVDC system with LCC and MMC installed in different poles. For example, the Skagerrak HVDC interconnections project adopted the voltage source converter on pole 4 and LCC on 
poles 1 to 3 [8]. (ii) The station-station hybrid HVDC system with LCC and MMC installed in different stations. The Kunliulong HVDC project, which transmits bulk hydropower from Yunnan province to load centers in Guangdong and Guangxi provinces through $1489 \mathrm{~km}$ overhead lines, is a practical example [9]. (iii) The in-station hybrid HVDC system with LCC and MMC installed in the same station. According to the connecting method of LCC and MMC, the in-station hybrid HVDC system can be further divided into: (a) The in-station hybrid HVDC system with LCC and MMC in series connection, e.g., the Baihetan HVDC project under planning in China. In this project, the inverter-station locating in Jiangsu province consists of LCC and MMC in series connection [10]. (b) The in-station hybrid HVDC system with LCC and MMC in parallel connection, which is currently at the academic research level [11].

For the cascaded LCC-MMC hybrid HVDC system, e.g., the Baihetan HVDC project, LCC and MMC are usually fed into two receiving AC systems with a certain electrical distance (interconnected by a tie line) to optimize the structure of the receiving power grid [7]. Thus, LCC and MMC are not only connected in series at the DC-side but also interact with each other at the AC-side, indicating that there is a complicated coupling between LCC and MMC. Considering the increasing penetration of renewable energy and power electronics, the $\mathrm{AC}$ system tends to weaken gradually [12]. Besides, the tripping of $\mathrm{AC}$ transmission lines by scheduled maintenance or occasional $\mathrm{AC}$ faults may also result in a temporary decrease of the strength of the AC system [13]. Existing literatures reveal that both LCC-HVDC and MMC-HVDC are subjected to instability issue when integrating with a weak AC system [12]-[14]. Thus, the cascaded LCC-MMC inverter may have a worse stability margin under weak $\mathrm{AC}$ systems integration due to the coupling between LCC and MMC. It is significant to identify the stable zone of the strength of the receiving $\mathrm{AC}$ systems for the cascaded LCC-MMC inverter to guide the planning and operation of a practical project.

The small-signal stability analysis of LCC-HVDC and MMC-HVDC has been well studied in recent years. References [15]-[18] developed the dynamic model of LCC based on the quasi-steady-state equations. But the transition of the valve current of LCC is assumed to be linear, which is not accurate. References [19]-[24] established sound small-signal models of $\mathrm{MMC}$, in which the internal harmonics of MMC, including the submodule capacitor voltage ripples and internal circulating currents, are considered. However, researches on the smallsignal stability of the hybrid HVDC systems are at the preliminary stage. Only [25]-[27] conducted related studies on

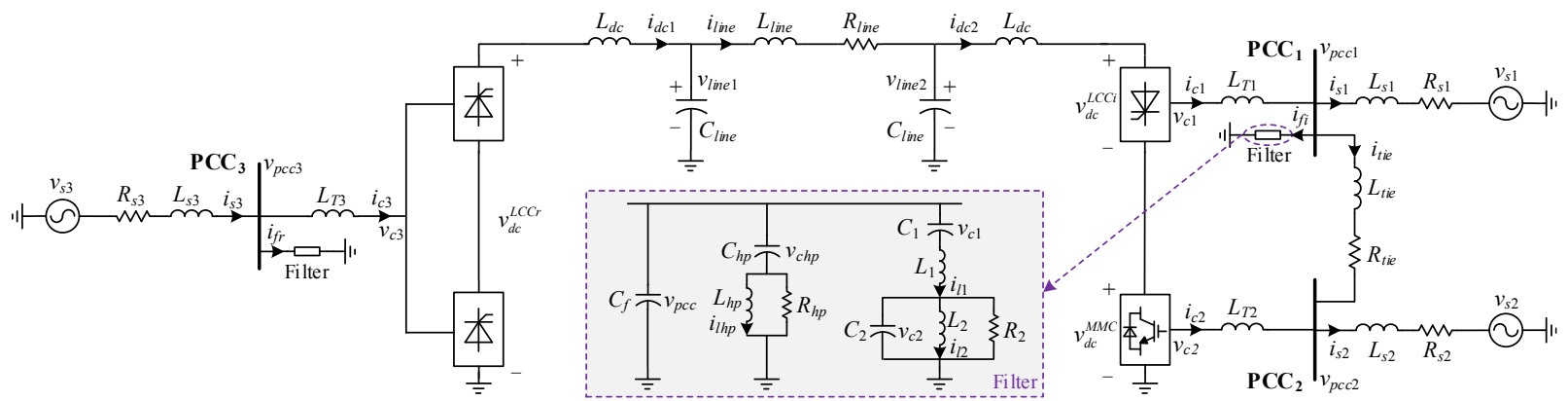

Fig. 2. Single line diagram of the cascaded LCC-MMC inverter based hybrid HVDC system. the station-station hybrid HVDC systems, revealing that interactions between different types of converters may induce instability of the system. Therefore, it is necessary to implement an investigation into the small-signal stability of the in-station hybrid HVDC system.

To overcome this challenge, a small-signal model of the cascaded LCC-MMC inverter based hybrid HVDC system is developed in this paper. Based on the eigenvalue analysis [28], the impact of the strength of the receiving $\mathrm{AC}$ systems quantified by short circuit ratio (SCR) and the proximity of the receiving AC systems on the small-signal stability of the system is investigated. The contributions of this paper are as follows:

1) A comprehensive small-signal model of the cascaded LCC-MMC hybrid HVDC system is established, in which a modified model of LCC, considering the actual sinusoidal variation of the valve current, is incorporated;

2) The feasible region of SCR to maintain the system stable under different tie line lengths is identified;

3) A supplementary coupling mitigation control is proposed to improve the stability of the system under weak AC systems integration.

The reminder of this paper is organized as follows: Section II describes the studied system. Section III establishes the small-signal model of the system, which is verified in Section IV. Eigenvalue analysis is carried out in Section V. Section VI proposes the supplementary control and a conclusion is conducted in Section VII.

\section{CASCADED LCC-MMC INVERTER BASED HYBRID HVDC SYSTEM}

\section{A. Main Circuit of HVDC system}

The schematic diagram of the cascaded LCC-MMC inverter based hybrid HVDC system studied in this paper is depicted in Fig. 1. The system adopts a traditional LCC based converter in the rectifier-station and the cascaded LCC-MMC converter in the inverter-station, where two sub-converters are connected to two receiving $\mathrm{AC}$ systems at points of common coupling (PCCs) joined via a tie line.

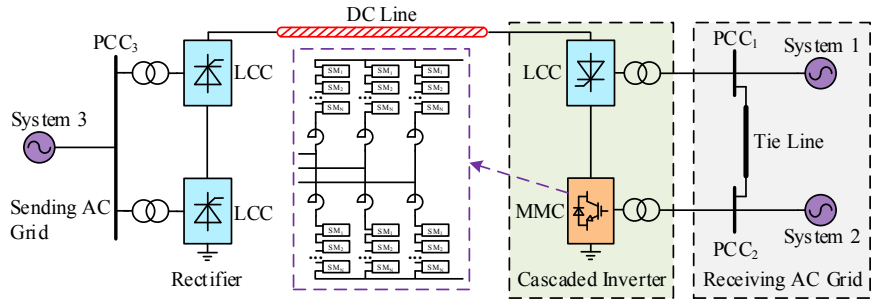

Fig. 1. Layout of the cascaded LCC-MMC inverter based hybrid HVDC system. 
The single line diagram of the cascaded LCC-MMC inverter based hybrid HVDC system is illustrated in Fig. 2. The AC systems are modelled using Thevenin's equivalent circuit, i.e., voltage source with series inductance and resistance. A $\pi$-type equivalent circuit is used to represent the $\mathrm{DC}$ line. The tie line between $\mathrm{PCC}_{1}$ and $\mathrm{PCC}_{2}$ is represented by series inductance and resistance. The interfaced transformers of converters are represented by their leakage inductance. The structure of the filter at $\mathrm{PCC}_{1}$ is shown below the DC line in Fig. 2, which consists of a fixed capacitor, a high pass filter, and a dual-tuned filter. Since the structure of the filter at $\mathrm{PCC}_{3}$ is the same as that at $\mathrm{PCC}_{1}$, it is not shown in Fig. 2.

\section{B. Layout of Control System}

The control system is comprised of PLLs and controllers of LCC and MMC.

Fig. 3 depicts the conventional structure of PLL, which is used to provide a phase angle reference to the controllers of $\mathrm{LCC}$ and MMC, in order to remain LCC and MMC synchronized with AC systems.

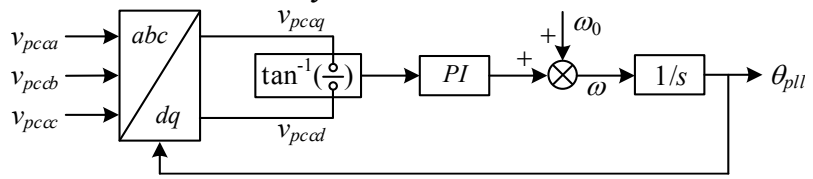

Fig. 3. Schematic diagram of PLL.

The schematic diagram of the controller of LCC inverter is depicted in Fig. 4, which employs a constant DC voltage control strategy to remain the DC voltage of LCC inverter constant in steady-state.

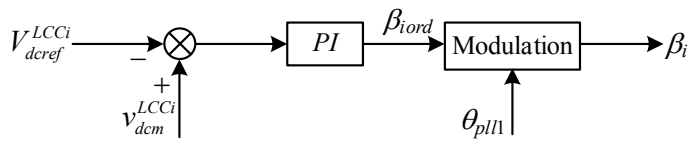

Fig. 4. Schematic diagram of the controller of LCC inverter.

Fig. 5 illustrates the controller of LCC rectifier, which maintains a constant rectifier-side DC current by a proportional-integral control strategy.

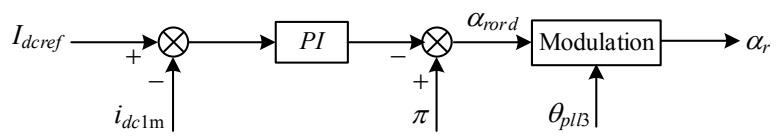

Fig. 5 Schematic diagram of controller of LCC in the rectifier-station.

Fig. 6 shows the controller of MMC, consisting of a traditional double closed-loop vector control and a circulating current suppression control, as illustrated in Fig. 6(a) and (b), respectively. The vector control comprises an outer voltage/power control loop and an inner AC current control loop. The outer loop control is utilized to regulate the DC voltage of $\mathrm{MMC}$ and $\mathrm{AC}$ voltage of $\mathrm{PCC}_{2}$. The inner control tracks the current reference value generated by the outer loop control and allows for the ability to suppress the DC fault current. The circulating current suppression control is exploited to eliminate the internal circulating current.

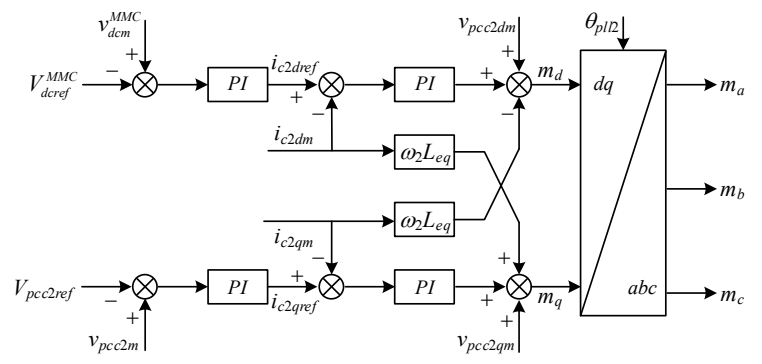

(a) Double closed-loop vector control

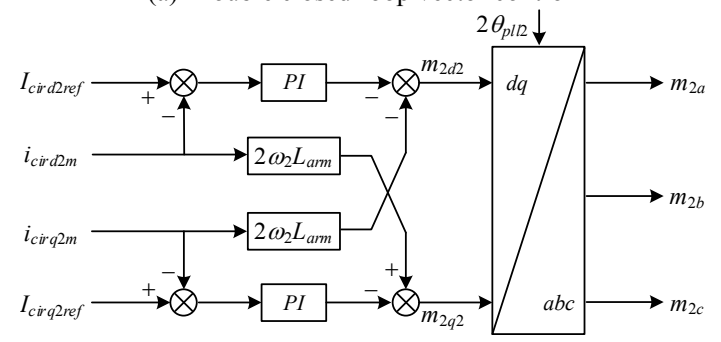

(b) Circulating current suppression control

Fig. 6. Schematic diagram of MMC controllers.

\section{LINEARIZED SMALL-SIGNAL MODEL}

\section{A. Description for Modelling Approach}

For the modelling of an MMC based DC grid, the interfaced equivalent circuit of MMC is usually used to facilitate the linking of MMC with the AC system and DC network [21]. Similar to this method, the interfaced equivalent circuits of both LCC and MMC will be deduced to address the interconnection between them.

\section{B. Interfaced Equivalent Circuit of LCC \\ 1) Inverter Mode}

The structure diagram of a six-pulse LCC inverter is shown in Fig. 7(a), where $V T_{1}$ to $V T_{6}$ are transistor valves. In a practical project, LCC inverter is usually comprised of multiple six-pulse units, and a six-pulse LCC inverter is displayed here for simplicity. Fig. 7(b) depicts the interfaced equivalent circuit of LCC inverter. From Fig. 7(b), LCC inverter is regarded as a controlled voltage source $e_{d c}^{L C C i}$ in series with resistance $R_{d c}^{L C C i}$ and inductance $L_{d c}^{L C C i}$ from the DC-side, whereas it is considered as a controlled current source from the $\mathrm{AC}$-side.

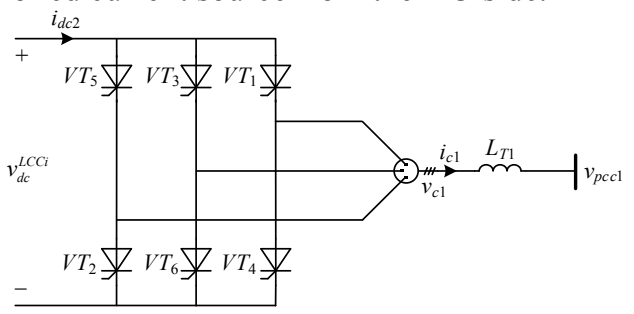

(a) Structure diagram of the six-pulse LCC inverter

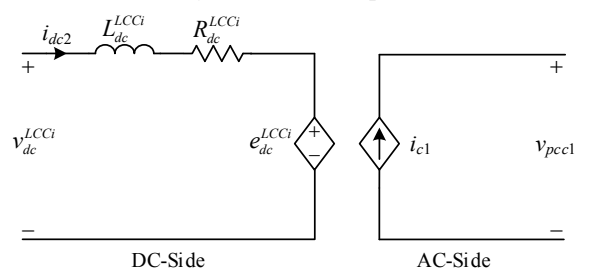

(b) Interfaced equivalent circuit diagram of the LCC inverter

Fig. 7. Schematic diagram of LCC inverter. 
The interfaced equivalent circuit of LCC inverter will be derived below. The DC voltage of LCC inverter $v_{d c}^{L C C i}$ can be represented by [29]:

$$
\begin{aligned}
v_{d c}^{L C C i} & =N_{b i}\left[\frac{3 \sqrt{3}}{\pi} v_{p c c 1} \cos \beta_{i}+\frac{3}{\pi} X_{T 1} i_{d c 2}+\left(2-\frac{3 \mu_{i}}{2 \pi}\right) L_{T 1} \frac{d i_{d c 2}}{d t}\right] \\
& =e_{d c}^{L C C i}+R_{d c}^{L C C i} i_{d c 2}+L_{d c}^{L C C i} \frac{d i_{d c 2}}{d t}
\end{aligned}
$$

where $N_{b i}$ is the number of six-pulse units making up LCC inverter; $\mu_{i}$ is the commutation overlap angle of LCC inverter, and it is calculated by:

$$
\mu_{i}=\beta_{i}-\cos ^{-1}\left(\cos \beta_{i}+\frac{2 X_{T 1} i_{d c 2}}{\sqrt{3} v_{p c c 1}}\right)
$$

Besides, from (1) we can get that $e_{d c}^{L C C i}=(3 \sqrt{3}$ $/ \pi) N_{b i} v_{p c c 1} \cos \beta_{i}, R_{d c}^{L C C i}=(3 / \pi) N_{b i} X_{T 1}, L_{d c}^{L C C i}=\left[2-3 \mu_{i} /(2 \pi)\right] N_{b i} L_{T 1}$.

Where $e_{d c}^{L C C i}$ is the ideal no-load DC voltage, $R_{d c}^{L C C i}$ is the equivalent commutation resistance, and $L_{d c}^{L C C i}$ is the converter transformer's equivalent DC inductance.

When calculating the AC current of LCC inverter based on the quasi-steady-state equations, the transition of current between involved valves during the commutation period is approximately considered to be linear. However, the actual current waveform is a sine wave. Thus, taking the actual sinusoidal variation of the valve current into consideration, the AC current of LCC inverter $i_{c 1}$ should be expressed as:

$$
\left\{\begin{array}{l}
i_{c 1 x}=\frac{2 \sqrt{3}}{\pi} N_{b i} i_{d c 2} \frac{\cos \left(\beta_{i}-\mu_{i}\right)+\cos \beta_{i}}{2} \\
i_{c 1 y}=\frac{2 \sqrt{3}}{\pi} N_{b i} i_{d c 2} \frac{\sin \left[2\left(\beta_{i}-\mu_{i}\right)\right]-\sin \left(2 \beta_{i}\right)+2 \mu_{i}}{4\left[\cos \left(\beta_{i}-\mu_{i}\right)-\cos \beta_{i}\right]}
\end{array}\right.
$$

\section{2) Rectifier Mode}

The interfaced equivalent circuit of the LCC rectifier is shown in Fig. 8, which is similar to that of the LCC inverter.

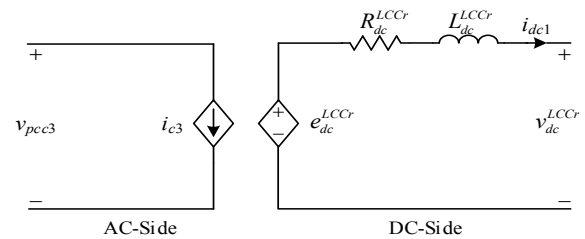

Fig. 8. Schematic diagram of LCC rectifier.

Therefore, the DC-side components can be obtained:

$$
\begin{aligned}
& e_{d c}^{L C C r}=\frac{3 \sqrt{3}}{\pi} N_{b r} v_{p c c 3} \cos \alpha_{r}, R_{d c}^{L C C r}=\frac{3}{\pi} N_{b r} X_{T 3}, \\
& L_{d c}^{L C C r}=\left(2-\frac{3 \mu_{r}}{2 \pi}\right) N_{b r} L_{T 3}
\end{aligned}
$$

The AC-side components are:

$$
\left\{\begin{array}{l}
i_{c 3 x}=\frac{2 \sqrt{3}}{\pi} N_{b r} i_{d c 1} \frac{\cos \alpha_{r}+\cos \left(\alpha_{r}+\mu_{r}\right)}{2} \\
i_{c 3 y}=-\frac{2 \sqrt{3}}{\pi} N_{b r} i_{d c 1} \frac{\sin \left(2 \alpha_{r}\right)-\sin \left[2\left(\alpha_{r}+\mu_{r}\right)\right]+2 \mu_{r}}{4\left[\cos \alpha_{r}-\cos \left(\alpha_{r}+\mu_{r}\right)\right]}
\end{array}\right.
$$

where $N_{b r}$ is the number of six-pulse units making up LCC rectifier, $\mu_{r}$ is the commutation overlap angle of LCC rectifier, and it is calculated by:

$$
\mu_{r}=-\alpha_{r}+\cos ^{-1}\left(\cos \alpha_{r}-\frac{2 X_{T 3} i_{d c 1}}{\sqrt{3} v_{p c c 3}}\right)
$$

\section{Interfaced Equivalent Circuit and Internal Dynamics of $M M C$}

Fig. 9(a) shows the structure diagram of MMC. $v_{p j}$ and $v_{n j}(j$ $=a, b, c)$ represent the upper and lower arm voltages, respectively. $i_{p j}$ and $i_{n j}$ represent the upper and lower arm currents, respectively. $i_{c i r j}$ is the internal circulating current. $L_{\text {arm }}$ and $R_{a r m}$ are respectively the arm inductance and resistance. $v_{p j}$ is the product of the total capacitor voltage of the upper arm $v_{c p j}^{\Sigma}$ and the modulation index of the upper arm $m_{p j}$, where $m_{p j}=(1$ $\left.-m_{j}+m_{2 j}\right) / 2 . v_{n j}$ is similar to $v_{p j}$ except for $m_{n j}=\left(1+m_{j}+m_{2 j}\right)$ / 2. Fig. 9(b) shows the interfaced equivalent circuit diagram of MMC. As illustrated in Fig. 9(b), the DC-side equivalent circuit of MMC is a controlled voltage source $e_{d c}^{M M C}$ in series with resistance $R_{d c}^{M M C}$ and inductance $L_{d c}^{M M C}$. And its AC-side equivalent circuit is a controlled voltage source $e_{c}$ in series with resistance $R_{e q}$ and inductance $L_{e q}$.

According to the internal and external dynamics, the 10order dynamic model of MMC in [21] is divided into two parts here. The AC current and DC current of MMC are considered as the state variables describing the external dynamics, whereas other variables are considered as those describing the internal dynamics. The detailed description of the internal dynamics of MMC can be referred to Appendix A. Based on the external dynamics of $\mathrm{MMC}$, its interfaced equivalent circuit will be derived.

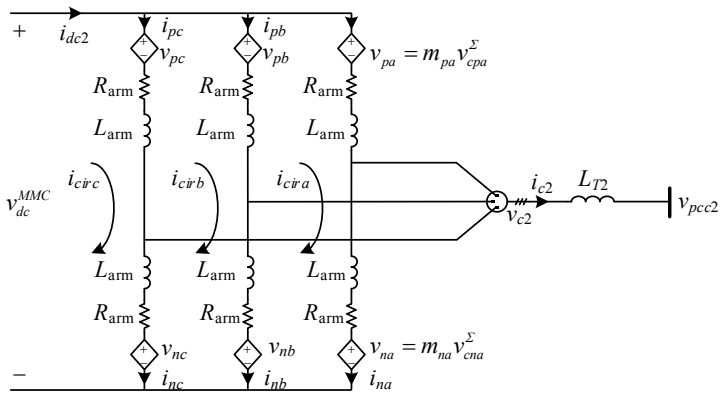

(a) Structure diagram of MMC

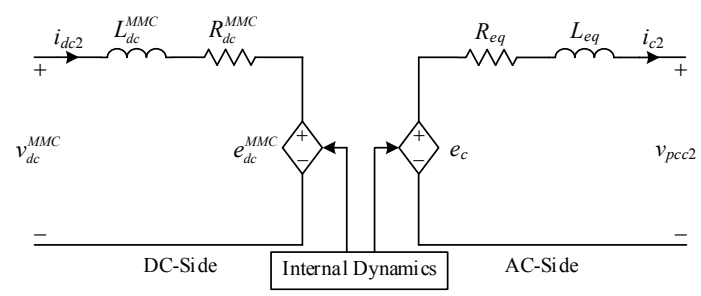

(b) Interfaced equivalent circuit of MMC

Fig. 9. Schematic diagram of MMC.

The external dynamics of MMC can be described as:

$$
\begin{aligned}
\frac{2}{3} L_{a r m} \frac{d i_{d c 2}}{d t} & =\frac{m_{2 x 2} v_{c p x 2}^{\Sigma}}{2}+\frac{m_{2 y 2} v_{c p y 2}^{\Sigma}}{2}+\frac{m_{x} v_{c p x}^{\Sigma}}{2}+\frac{m_{y} v_{c p y}^{\Sigma}}{2} \\
& -v_{c p 0}^{\Sigma}-\frac{2}{3} R_{a r m} i_{d c 2}+v_{d c}^{M M C}
\end{aligned}
$$




$$
\left\{\begin{aligned}
\frac{L_{a r m}}{2} \frac{d i_{c 2 x}}{d t}= & \frac{m_{x} v_{c p x 2}^{\Sigma}}{4}+\frac{m_{y} v_{c p y 2}^{\Sigma}}{4}+\frac{\left(m_{2 x 2}-2\right) v_{c p x}^{\Sigma}}{4}+\frac{m_{2 y 2} v_{c p y}^{\Sigma}}{4} \\
& +\frac{m_{x} v_{c p 0}^{\Sigma}}{2}-\frac{R_{a r m}}{2} i_{c 2 x}+\omega_{0} i_{c 2 y}-v_{c 2 x} \\
\frac{L_{a r m}}{2} \frac{d i_{c 2 y}}{d t}= & -\frac{m_{y} v_{c p x 2}^{\Sigma}}{4}+\frac{m_{x} v_{c p y 2}^{\Sigma}}{4}+\frac{m_{2 y 2} v_{c p x}^{\Sigma}}{4}-\frac{\left(m_{2 x 2}+2\right) v_{c p y}^{\Sigma}}{4} \\
& +\frac{m_{y} v_{c p 0}^{\Sigma}}{2}-\frac{R_{a r m}}{2} i_{c 2 y}-\omega_{0} i_{c 2 x}-v_{c 2 y}
\end{aligned}\right.
$$

Equations (7) and (8) represent the dynamics of DC current and $\mathrm{AC}$ current of MMC, respectively. Rearranging (7) and (8) yields:

$$
\begin{gathered}
v_{d c}^{M M C}=e_{d c}^{M M C}+R_{d c}^{M M C} i_{d c 2}+L_{d c}^{M M C} \frac{d}{d t} i_{d c 2} \\
\left\{\begin{array}{l}
v_{c 2 x}=e_{c x}-R_{e q} i_{c 2 x}-L_{e q} \frac{d}{d t} i_{c 2 x}+\omega_{0} i_{c 2 y} \\
v_{c 2 y}=e_{c y}-R_{e q} i_{c 2 y}-L_{e q} \frac{d}{d t} i_{c 2 y}-\omega_{0} i_{c 2 x}
\end{array}\right.
\end{gathered}
$$

where,

$$
\begin{gathered}
e_{d c}^{M M C}=-\frac{m_{2 x 2} v_{c p x 2}^{\Sigma}}{2}-\frac{m_{2 y 2} v_{c p y 2}^{\Sigma}}{2}-\frac{m_{x} v_{c p x}^{\Sigma}}{2}-\frac{m_{y} v_{c p y}^{\Sigma}}{2}+v_{c p 0}^{\Sigma}, \\
R_{d c}^{M M C}=\frac{2}{3} R_{a r m}, L_{d c}^{M M C}=\frac{2}{3} L_{a r m} \\
e_{c x}=\frac{m_{x} v_{c p x 2}^{\Sigma}}{4}+\frac{m_{y} v_{c p y 2}^{\Sigma}}{4}+\frac{\left(m_{2 x 2}-2\right) v_{c p x}^{\Sigma}}{4}+\frac{m_{2 y 2} v_{c p y}^{\Sigma}}{4}+\frac{m_{x} v_{c p 0}^{\Sigma}}{2} \\
e_{c y}=-\frac{m_{y} v_{c p x 2}^{\Sigma}}{4}+\frac{m_{x} v_{c p y 2}^{\Sigma}}{4}+\frac{m_{2 y 2} v_{c p x}^{\Sigma}}{4}-\frac{\left(m_{2 x 2}+2\right) v_{c p y}^{\Sigma}}{4}+\frac{m_{y} v_{c p 0}^{\Sigma}}{2} \\
R_{e q}=\frac{1}{2} R_{a r m}, L_{e q}=\frac{1}{2} L_{a r m}
\end{gathered}
$$

It is intuitive to obtain the interfaced equivalent circuit of MMC in Fig. 9 (b) from (9) and (10). In addition, $L_{e q}$ in Fig. 9 (b) should be modified as $L_{a r m} / 2+L_{T 2}$, considering the leakage inductance of the transformer.

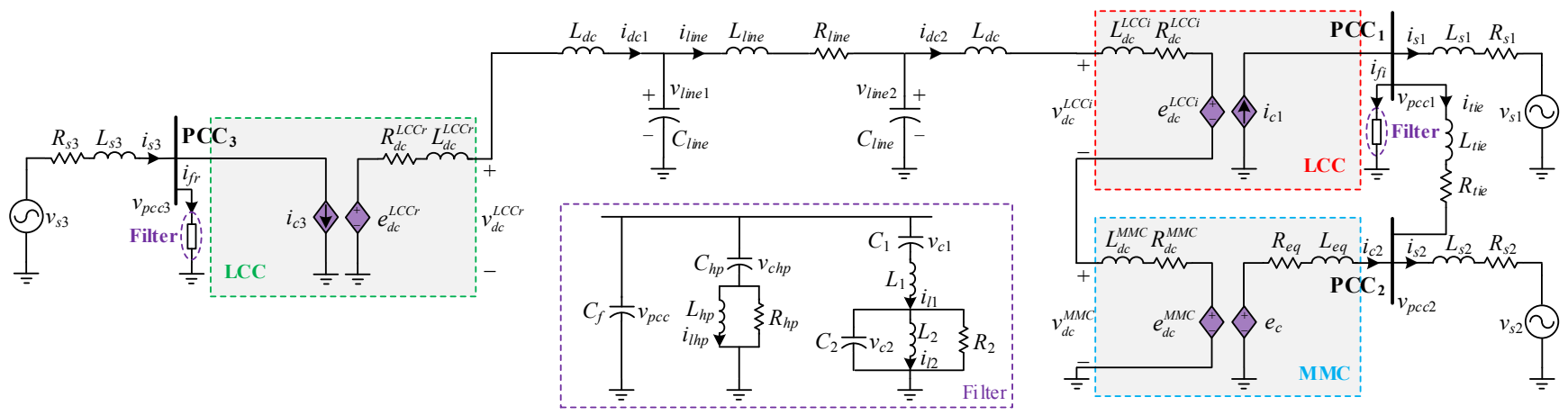

Fig. 10. Equivalent circuit diagram of cascaded LCC-MMC inverter based hybrid HVDC system.

\section{Overall Small-Signal Model}

Utilizing the interfaced equivalent circuits of LCC and MMC deduced above, the interconnection between LCC and MMC, and the linking of them with the AC system and DC line are realized, as depicted in Fig. 10.

\section{1) DC-Side Modelling}

From Fig. 10, the dynamic of DC current flowing through both LCC inverter and MMC $i_{d c 2}$ can be obtained:

$$
L_{d c}^{t o t} \frac{d i_{d c 2}}{d t}=v_{\text {line } 2}-e_{d c}^{L C C i}-e_{d c}^{M M C}-\left(R_{d c}^{L C C i}+R_{d c}^{M M C}\right) i_{d c 2}
$$

where $L_{d c}^{t o t}=L_{d c}+L_{d c}^{L C C i}+L_{d c}^{M M C}$.

According to (13), the expressions of DC voltage of LCC inverter can be derived as:

$$
\begin{aligned}
v_{d c}^{L C C i}= & e_{d c}^{L C C i}+i_{d c 2} R_{d c}^{L C C i}+L_{d c}^{L C C i} \frac{d i_{d c 2}}{d t}=\left[\frac{e_{d c}^{L C C i}+i_{d c 2} R_{d c}^{L C C i}}{L_{d c}^{L C C i}}+\right. \\
& \left.\frac{v_{\text {line } 2}-e_{d c}^{M M C}-i_{d c 2} R_{d c}^{M M C}}{L_{d c}+L_{d c}^{M M C}}\right] /\left(\frac{1}{L_{d c}^{L C C i}}+\frac{1}{L_{d c}+L_{d c}^{M M C}}\right)
\end{aligned}
$$

When calculating the DC voltage of LCC inverter, existing literatures usually ignore the impact of $L_{d c}^{L C C i}$, which is only suitable for steady-state analysis [17][18]. The impact of $L_{d c}^{L C C i}$ on the DC voltage of LCC inverter is considered in this paper, as shown in (14).

The DC voltage of MMC $v_{d c}^{M M C}$ can be derived in a similar way and will not be repeated here.
The dynamic behavior of the DC line is described by three state variables, i.e., $i_{\text {line }}, v_{\text {line } 1}$ and $v_{\text {line } 2}$. Their dynamic equations are as follows:

$$
\left\{\begin{array}{l}
L_{\text {line }} \frac{d i_{\text {line }}}{d t}=v_{\text {line } 1}-v_{\text {line } 2}-i_{\text {line }} R_{\text {line }} \\
C_{\text {line }} \frac{d v_{\text {line } 1}}{d t}=i_{d c 1}-i_{\text {line }} \\
C_{\text {line }} \frac{d v_{\text {line } 2}}{d t}=i_{\text {line }}-i_{d c 2}
\end{array}\right.
$$

The dynamic of rectifier-side DC current $i_{d c 1}$ can be represented as:

$$
\left(L_{d c}+L_{d c}^{L C C r}\right) \frac{d i_{d c 1}}{d t}=e_{d c}^{L C C r}-R_{d c}^{L C C r} i_{d c 1}-v_{\text {line } 1}
$$

\section{2) AC-Side Modelling}

From Fig. 10, the dynamic model of the receiving AC system $i(i=1,2)$ can be expressed as:

$$
\left\{\begin{array}{l}
L_{s i} \frac{d i_{s i x}}{d t}=v_{p c c i x}-V_{s i x}-i_{s i x} R_{s i}+\omega_{0} L_{s i} i_{s i y} \\
L_{s i} \frac{d i_{s i y}}{d t}=v_{p c c i y}-V_{s i y}-i_{s i y} R_{s i}-\omega_{0} L_{s i} i_{s i x}
\end{array}\right.
$$




$$
\left\{\begin{array}{l}
L_{t i e} \frac{d i_{t i e x}}{d t}=v_{p c c 1 x}-v_{p c c 2 x}-i_{t i e x} R_{t i e}+\omega_{0} L_{t i e} i_{t i e y} \\
L_{t i e} \frac{d i_{t i e y}}{d t}=v_{p c c 1 y}-v_{p c c 2 y}-i_{t i e y} R_{t i e}-\omega_{0} L_{t i e} i_{t i e x}
\end{array}\right.
$$

The dynamic of $\mathrm{AC}$ voltage of $\mathrm{PCC}_{1}$, which is the dynamic of the fixed capacitor in the filter at $\mathrm{PCC}_{1}$, can be represented as:

$$
\left\{\begin{array}{l}
C_{f}^{i} \frac{d v_{p c c 1 x}}{d t}=i_{f i x}-i_{l h p x}^{i}-\frac{v_{p c c 1 x}-v_{c h p x}^{i}}{R_{h p}^{i}}-i_{l 1 x}^{i}+\omega_{0} C_{f}^{i} v_{p c c 1 y} \\
C_{f}^{i} \frac{d v_{p c c 1 y}}{d t}=i_{f y y}-i_{l h p y}^{i}-\frac{v_{p c c 1 y}-v_{c h p y}^{i}}{R_{h p}^{i}}-i_{l 1 y}^{i}-\omega_{0} C_{f}^{i} v_{p c c 1 x}
\end{array}\right.
$$

where $i_{f i}=i_{c 1}-i_{s 1}-i_{t i e}$.

The dynamics of other equipment in the filter at $\mathrm{PCC}_{1}$, i.e., the high-pass filter and the dual-tuned filter, can be represented by the differential equations of corresponding capacitor voltages and inductor currents, which are left out here.

The $\mathrm{AC}$ voltage of $\mathrm{PCC}_{2} v_{p c c 2}$ is the interfaced variable between $\mathrm{MMC}$ and the $\mathrm{AC}$-side and its expression is deduced as:

$$
\begin{aligned}
v_{p c c 2}= & e_{c}-R_{e q}\left(i_{t i e}-i_{s 2}\right)-L_{e q} \frac{d\left(i_{t i e}-i_{s 2}\right)}{d t}=\left\{\frac{v_{p c c 1}-i_{t i e} R_{t i e}}{L_{t i e}}+\right. \\
& \left.\frac{v_{s 2}+i_{s 2} R_{s 2}}{L_{s 2}}+\frac{e_{c}-\left(i_{t i e}-i_{s 2}\right) R_{e q}}{L_{e q}}\right\} /\left(\frac{1}{L_{t i e}}+\frac{1}{L_{s 2}}+\frac{1}{L_{e q}}\right)
\end{aligned}
$$

The dynamic behavior of the sending AC system can be expressed as:

$$
\left\{\begin{array}{l}
L_{s 3} \frac{d i_{s 3 x}}{d t}=V_{s 3 x}-v_{p c c 3 x}-i_{s 3 x} R_{s 3}+\omega_{0} L_{s 3} i_{s 3 y} \\
L_{s 3} \frac{d i_{s 3 y}}{d t}=V_{s 3 y}-v_{p c c 3 y}-i_{s 3 y} R_{s 3}-\omega_{0} L_{s 3} i_{s 3 x}
\end{array}\right.
$$

\section{3) Small-Signal Modelling}

The detailed modelling on the control system, including PLL, controller of LCC inverter, controller of LCC rectifier and controller of MMC, can be refer to Appendix A.

The aforementioned nonlinear dynamic model of the cascaded LCC-MMC inverter based hybrid HVDC system can be expressed in the general form of:

$$
\frac{d \boldsymbol{x}}{d t}=\boldsymbol{f}(\boldsymbol{x}, \boldsymbol{u})
$$

where $\boldsymbol{x}$ and $\boldsymbol{u}$ are the state and input vectors, respectively; $\boldsymbol{x}$ is

\begin{tabular}{|c|c|}
\hline Subsystems & State variables \\
\hline AC system 1 & $\begin{array}{l}i_{s 1 x}, i_{s 1 y}, v_{p c c 1 x}, v_{p c c 1 y}, v_{c h p}^{i}, v_{c h p y}^{i}, v_{c 1 x}^{i}, v_{c 1 y}^{i}, \\
v_{c 2 x}^{i}, v_{c 2 y}^{i}, i_{l h p x}^{i}, i_{l h p y}^{i}, i_{l 1 x}^{i}, i_{l 1 y}^{i}, i_{l 2 x}^{i}, i_{l 2 y}^{i}\end{array}$ \\
\hline AC system 2 & $i_{s 2 x}, i_{s 2 y}$ \\
\hline AC system 3 & $\begin{array}{l}i_{s 3 x}, i_{s 3 y}, v_{p c c 3 x}, v_{p c c 3 y}, v_{c h p p}^{r}, v_{c h p y}^{r}, v_{c 1 x}^{r}, v_{c 1 y}^{r}, \\
v_{c 2 x}^{r}, v_{c 2 y}^{r}, i_{l h p x}^{r}, i_{l h p y}^{r}, i_{l 1 x}^{r}, i_{l 1 y}^{r}, i_{l 2 x}^{r}, i_{l 2 y}^{r}\end{array}$ \\
\hline Tie line & $i_{\text {tiex }}, i_{\text {tiey }}$ \\
\hline DC line & $i_{d c 1}, i_{d c 2}, i_{\text {line }}, v_{\text {line } 1}, v_{\text {line } 2}$ \\
\hline MMC & $v_{c p x 22}^{\Sigma}, v_{c p y 2}^{\Sigma}, v_{c p x}^{\Sigma}, v_{c p y}^{\Sigma}, v_{c p 00}^{\Sigma}, i_{c i r x 2}, i_{c i r y 2}$ \\
\hline $\mathrm{PLL}_{1} / \mathrm{PLL}_{2} / \mathrm{PLL}_{3}$ & $x_{p l l 1}, \theta_{p l l 1} / x_{p l l 2}, \theta_{p l l 2} / x_{p l l 3}, \theta_{p l l 3}$ \\
\hline
\end{tabular}
a $72 \times 1$ vector; $\boldsymbol{u}=\left[v_{d c r e f}^{L C C i}, I_{d c r e f}, v_{d c r e f}^{M M C}, v_{p c c 2 r e f}\right]^{\mathrm{T}}$ is a $4 \times 1$ vector.

The state variables of the system are summarized in Table I in detail.

TABLE I

STATE VARIABLES

\begin{tabular}{l|l}
\hline \hline Controller of LCC inverter & $v_{d c m}^{L C C}, x_{i}$ \\
\hline Controller of LCC rectifier & $i_{d c 1 m}, x_{r}$ \\
\hline \multirow{2}{*}{ Controller of MMC } & $v_{d c m}^{M M C}, v_{p c c 2 m}, v_{p c c 2 d m}, v_{p c c 2 q m}, i_{c 2 d m}, i_{c 2 q m}$, \\
& $i_{c i r d 2 m}, i_{c i r q 2 m}, x_{o d}, x_{o q}, x_{i d}, x_{i q}, x_{c d}, x_{c q}$ \\
\hline \hline
\end{tabular}

By linearizing (22) around the steady-state operating point, the linearized small-signal model can be presented as follow:

$$
\frac{d \Delta \boldsymbol{x}}{d t}=\boldsymbol{A} \Delta \boldsymbol{x}+\boldsymbol{B} \Delta \boldsymbol{u}
$$

where $\boldsymbol{A}$ and $\boldsymbol{B}$ are the state and input matrices, respectively; $\boldsymbol{A}$ is a $72 \times 72$ matrix; $\boldsymbol{B}$ is a $72 \times 4$ matrix. The expressions of $\boldsymbol{A}$ and $\boldsymbol{B}$ could be easily generated from the linearization of (22).

\section{SMall-Signal Model Verification}

A detailed electromagnetic transient (EMT) model of the system depicted in Fig. 2 is implemented in PSCAD/EMTDC. The time-domain responses obtained from the linearized smallsignal model established in MATLAB/Simulink are then compared with those obtained from the detailed EMT model. System parameters for the verification are listed in Table II and

\begin{tabular}{|c|c|c|}
\hline \multicolumn{2}{|c|}{ Parameters } & Values \\
\hline $\mathrm{PLL}_{1}$ & $k_{p p l l 1}, k_{i p l l 1}$ & 10,50 \\
\hline $\mathrm{PLL}_{2}$ & $k_{p p l l 2}, k_{i p l l 2}$ & 80,500 \\
\hline $\mathrm{PLL}_{3}$ & $k_{p p l l 3}, k_{i p l l 3}$ & 10,50 \\
\hline Controller of LCC inverter & $k_{p i}, k_{i i}$ & 1,100 \\
\hline Controller of LCC rectifier & $k_{p r}, k_{i r}$ & 5,100 \\
\hline \multirow{4}{*}{ Controller of MMC } & $k_{\text {pod }}, k_{\text {iod }}$ & 4,100 \\
\hline & $k_{p o q}, k_{i o q}$ & $0.5,50$ \\
\hline & $k_{p i d}, k_{p i q}$ & 1,100 \\
\hline & $k_{p i q}, k_{i q q}$ & 1,100 \\
\hline
\end{tabular}
Table III.

TABLE II

MAIN CIRCUIT PARAMETERS

\begin{tabular}{l|l}
\hline \multicolumn{1}{c}{ Parameters } & \multicolumn{1}{c}{ Values } \\
\hline Rated DC current of LCC rectifier $i_{d c 1}$ & $2 \mathrm{kA}$ \\
\hline Rated DC voltage of LCC inverter $v_{d c}^{L C C i}$ & $400 \mathrm{kV}$ \\
\hline Rated DC voltage of MMC $v_{d c}^{M M C}$ & $400 \mathrm{kV}$ \\
\hline Voltage of AC system $i v_{s i}(i=1,2,3)$ & $500 \mathrm{kV}$ \\
\hline Resistance and inductance of AC system 1 & $15.5043 \Omega, 0.3948$ \\
$R_{s 1}, L_{s 1}$ & $\mathrm{H}$ \\
\hline Resistance and inductance of AC system 2 & $15.5043 \Omega, 0.3948$ \\
$R_{s 2}, L_{s 2}$ & $\mathrm{H}$ \\
\hline Resistance and inductance of AC system 3 & $7.7522 \Omega, 0.1974$ \\
$R_{s 3}, L_{s 3}$ & $\mathrm{H}$ \\
\hline Tie line resistance $R_{\text {tie }}$ & $1.4 \Omega$ \\
\hline Tie line inductance $L_{\text {tie }}$ & $0.043 \mathrm{H}$ \\
\hline $\begin{array}{l}\text { LCC inverter's transformer leakage } \\
\text { inductance } L_{T 1}\end{array}$ & $0.18 \mathrm{pu}$ \\
\hline MMC's transformer leakage inductance $L_{T 2}$ & $0.1 \mathrm{pu}$ \\
\hline LCC rectifier's transformer leakage & $0.18 \mathrm{pu}$ \\
inductance $L_{T 3}$ & 200 \\
\hline Submodule number of MMC $N_{s m}$ & $0.2 \Omega$ \\
\hline Arm resistance of MMC $R_{a r m}$ & $0.035 \mathrm{H}$ \\
\hline Arm inductance of MMC $L_{a r m}$ & $13.3 \mathrm{mF}$ \\
\hline Submodule capacitance $C_{s m}$ & $0.3 \mathrm{H}$ \\
\hline DC current-limiting inductance $L_{d c}$ & $10 \Omega$ \\
\hline DC line resistance $R_{\text {line }}$ & $1.62 \mathrm{H}$ \\
\hline DC line inductance $L_{\text {line }}$ & $13 \mu \mathrm{F}$ \\
\hline DC line capacitance $C_{\text {line }}$ & \\
\hline \hline &
\end{tabular}

TABLE III

CONTROL SYSTEM PARAMETERS 


\begin{tabular}{l|l|l}
\hline \hline & $k_{p c d}, k_{i c d}$ & $0.5,50$ \\
\cline { 2 - 3 } & $k_{p c q}, k_{i c q}$ & $0.5,50$ \\
\hline \hline
\end{tabular}

The parameters of the $\mathrm{AC}$ filter \& reactive power compensation equipment for LCC and the parameters of feedback filters are detailed in Appendix B.

The comparison of time-domain responses between the EMT and small-signal models is shown in Fig. 11. At $t=0 \mathrm{~s}$, the system is operating at the rated operating point $\left(v_{\text {dcref }}^{L C C i}=I_{\text {dcref }}=\right.$ $v_{\text {dcref }}^{M M C}=v_{\text {pcceref }}=1 \mathrm{pu}$ ). At $t=0.5 \mathrm{~s}$, a step change from $1 \mathrm{pu}$ to $0.975 \mathrm{pu}$ is imposed on the DC voltage reference value of MMC $v_{\text {dcref }}^{M M C}$. Fig. 11(a)-(f) depict the time-domain responses of the DC voltage of LCC $v_{d c}^{L C C i}$, DC voltage of MMC $v_{d c}^{M M C}$, AC voltage of $\mathrm{PCC}_{2} v_{p c c 2}$, total capacitor voltage of MMC $v_{c p a}^{\Sigma}$ (upper arm of phase $a$ ), inner loop d-axis current of MMC, and inner loop qaxis current of MMC, respectively. Where, the legend "EMT" and "SS" in Fig. 11 refer to the EMT model and small-signal model, respectively.

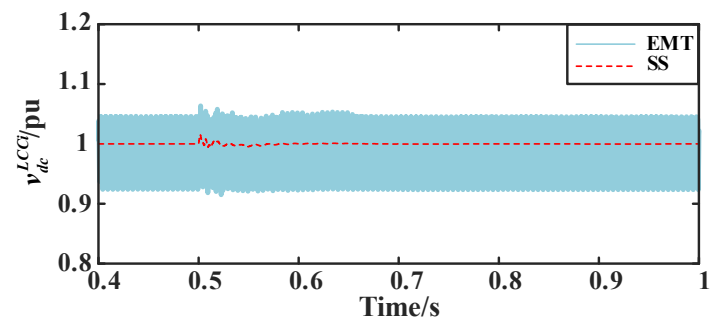

(a) DC voltage of LCC

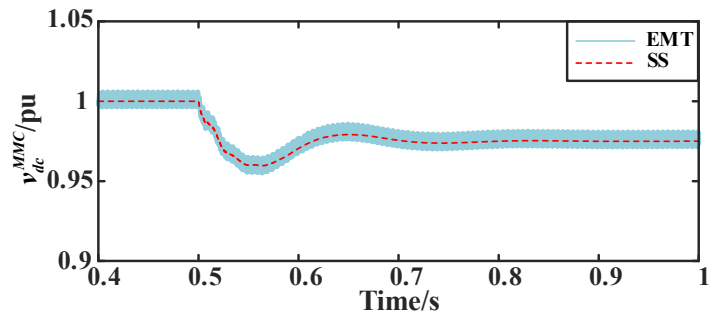

(b) DC voltage of MMC

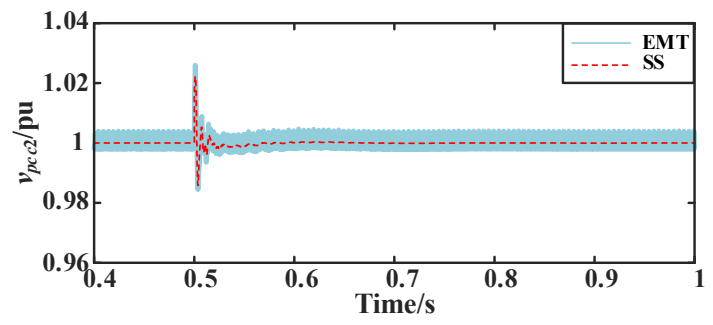

(c) AC voltage of $\mathrm{PCC}_{2}$

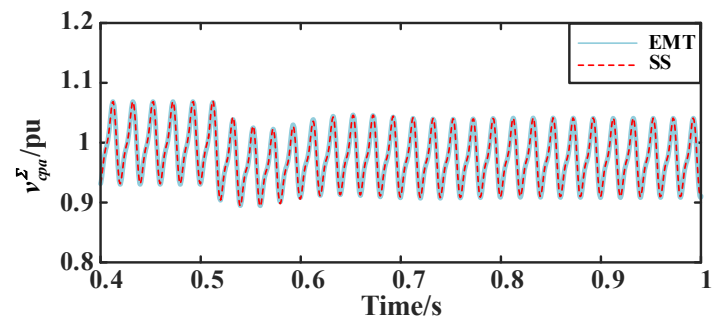

(d) Total capacitor voltage of MMC

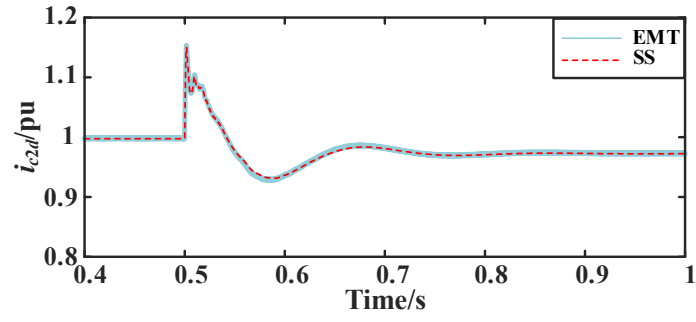

(e) Inner loop $d$-axis current of MMC

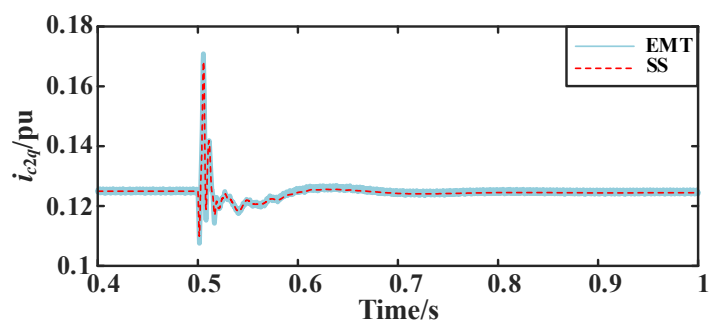

(f) Inner loop $q$-axis current of MMC

Fig. 11. Comparison of time-domain responses.

It can be observed from Fig. 11 that the time-domain responses from the small-signal model are in close agreement with those from the EMT model, which indicates that the accuracy of the small-signal model is acceptable. Since the EMT model simulates the switching process, its time-domain responses have additional high-frequency components.

\section{INVESTIGATION INTO IMPACT OF STRENGTH AND PROXIMITY OF RECEIVING AC GRIDS}

Fig. 12 shows the geographic diagram of the Baihetan HVDC project under planning, which will transmit largecapacity hydropower from Sichuan province to Jiangsu province. With the rapid growth of offshore wind power in Jiangsu province, the strength of Jiangsu power grid is gradually weakening. Therefore, this section investigates the impact of the strength of the receiving $\mathrm{AC}$ grids on the cascaded LCC-MMC inverter based hybrid HVDC system and determines the stable zone of the strength of the receiving $\mathrm{AC}$ systems, in order to prevent the HVDC link from being fed into a too weaker AC grid and causing instability. Moreover, the impact of the proximity of the receiving $\mathrm{AC}$ grids is also analyzed in this section.

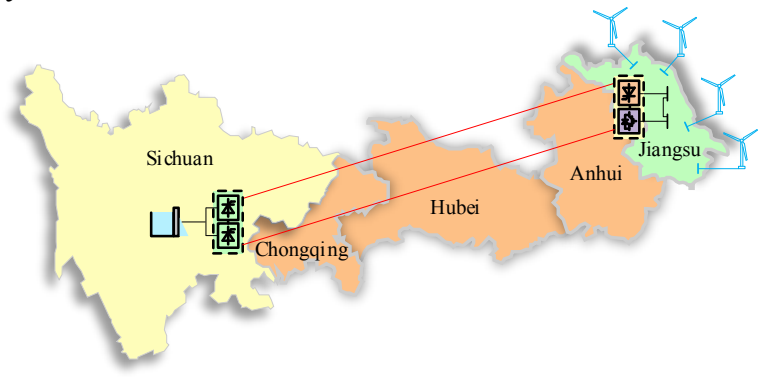

Fig. 12 Geographic diagram of Baihetan HVDC project.

\section{A. Strength of Receiving AC Grids}

Table IV lists the eigenvalues of the cascaded LCC-MMC inverter based hybrid HVDC system. Only the weak damping modes of the system (damping ratio $<10 \%$ ) are shown here, and they are arranged in the order of damping ratio from low to 
high. It can be concluded from the following analysis that the mode 9 is the dominant mode of the system.

TABLE IV

SYSTEM EIGENVALUES

\begin{tabular}{l|l|l|l}
\hline \hline Mode No. & Eigenvalue & $\begin{array}{c}\text { Damping } \\
\text { Ratio }\end{array}$ & $\begin{array}{c}\text { Oscillation } \\
\text { Frequency }\end{array}$ \\
\hline 1 & $-232.95 \pm 4866.77 \mathrm{i}$ & $4.78 \%$ & $774.57 \mathrm{~Hz}$ \\
\hline 2 & $-235.89 \pm 4868.59 \mathrm{i}$ & $4.84 \%$ & $774.86 \mathrm{~Hz}$ \\
\hline 3 & $-29.66 \pm 586.50 \mathrm{i}$ & $5.05 \%$ & $93.34 \mathrm{~Hz}$ \\
\hline 4 & $-232.67 \pm 4248.68 \mathrm{i}$ & $5.47 \%$ & $676.20 \mathrm{~Hz}$ \\
\hline 5 & $-237.44 \pm 4252.51 \mathrm{i}$ & $5.57 \%$ & $676.81 \mathrm{~Hz}$ \\
\hline 6 & $-37.27 \pm 563.81 \mathrm{i}$ & $6.60 \%$ & $89.73 \mathrm{~Hz}$ \\
\hline 7 & $-114.46 \pm 1579.99 \mathrm{i}$ & $7.23 \%$ & $251.46 \mathrm{~Hz}$ \\
\hline 8 & $-74.46 \pm 1003.64 \mathrm{i}$ & $7.40 \%$ & $159.73 \mathrm{~Hz}$ \\
\hline 9 & $-24.83 \pm 321.79 \mathrm{i}$ & $7.69 \%$ & $51.21 \mathrm{~Hz}$ \\
\hline 10 & $-115.39 \pm 1466.02 \mathrm{i}$ & $7.85 \%$ & $233.32 \mathrm{~Hz}$ \\
\hline 11 & $-36.88 \pm 421.42 \mathrm{i}$ & $8.72 \%$ & $67.07 \mathrm{~Hz}$ \\
\hline \hline
\end{tabular}

To evaluate the influence of the strength of the receiving AC grids, the following three scenarios are considered: (i) $\mathrm{SCR}_{1}$ varies and $\mathrm{SCR}_{2}$ remains constant $\left(\mathrm{SCR}_{2}=2.5\right)$; (ii) $\mathrm{SCR}_{2}$ varies and $\mathrm{SCR}_{1}$ remains constant $\left(\mathrm{SCR}_{1}=2.5\right)$; (iii) $\mathrm{SCR}_{1}$ and $\mathrm{SCR}_{2}$ vary simultaneously. The length of the tie line is $50 \mathrm{~km}$ in the above three scenarios. The root loci of three scenarios are depicted in Fig. 13 (a)-(c).

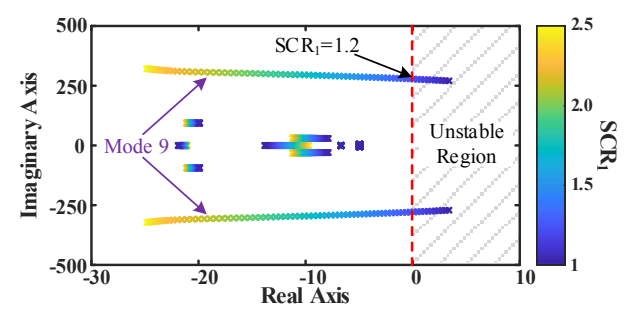

(a) $\mathrm{SCR}_{1}$ varies

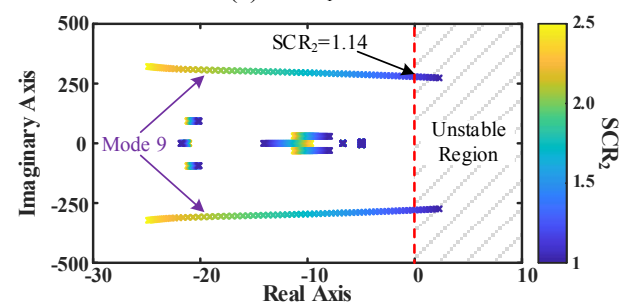

(b) $\mathrm{SCR}_{2}$ varies

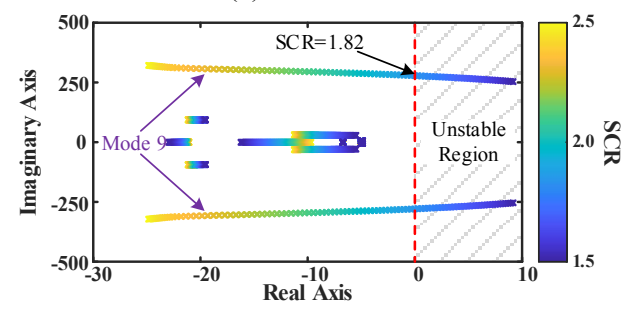

(c) $\mathrm{SCR}_{1}$ and $\mathrm{SCR}_{2}$ vary simultaneously

Fig. 13. Root loci of system with SCR varies (tie length $=50 \mathrm{~km}$ ).

Fig. 13(a) shows that the dominant mode of the system moves towards the unstable region with the decrease of $\mathrm{SCR}_{1}$, resulting in the system instability when $\mathrm{SCR}_{1}<1.2$. Similar conclusion is also drawn in Fig. 13(b), i.e., the system gets into an unstable condition when $\mathrm{SCR}_{2}<1.14$. It should be noted that despite scenario 1 and scenario 2 are set up symmetrically, the minimum acceptable SCR of AC grid 1 is not the same as that of $\mathrm{AC}$ grid 2 due to that they are connected to different types of converters. The minimum acceptable SCR of AC grid 2 is less than that of $\mathrm{AC}$ grid 1, indicating that $\mathrm{MMC}$ could tolerate a weaker AC grid than LCC. From Fig. 13(c), with $\mathrm{SCR}_{1}$ and $\mathrm{SCR}_{2}$ decreasing simultaneously, the small-signal stability margin of the system also declines, and the system becomes unstable when SCR $<1.82$.

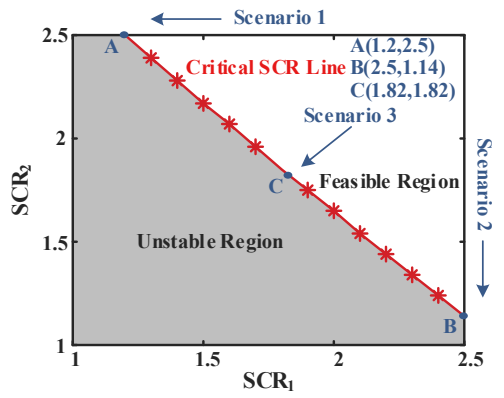

Fig. 14. Feasible region of SCR (tie length $=50 \mathrm{~km}$ )

By setting up more scenarios, the feasible region of SCR to ensure the system stable is determined in Fig. 14. The solid red line in Fig. 14 is referred to as the critical SCR line and represents the minimum acceptable $\mathrm{SCR}$ when $\mathrm{SCR}_{1}$ or $\mathrm{SCR}_{2}$ vary. For example, points $\mathrm{A}, \mathrm{B}$, and $\mathrm{C}$ on the line correspond to the minimum acceptable SCR of scenarios 1, 2, and 3, respectively. Note that the critical SCR line is a straight line, indicating there is a linear constraint between the minimum acceptable $\mathrm{SCR}_{1}$ and $\mathrm{SCR}_{2}$. In addition, the slope of the critical SCR line is less than -1 , which also implies MMC allows for the ability to be connected to a weaker AC grid. The critical SCR line divides the entire region of SCR into two. The upper part of the line represents the feasible region of SCR and the lower one represents the unstable region. The HVDC link should be fed into the receiving AC systems which strength is locating in the feasible region, to avoid instability.

\section{B. Proximity of Receiving AC Grids}

The root loci of the system with tie line length varying from $1 \mathrm{~km}$ to $100 \mathrm{~km}$ under three SCR configurations, are shown in Fig. 15(a)-(c), so as to assess the impact of the proximity of the receiving $\mathrm{AC}$ grids on the small-signal stability of the system: (i) $\mathrm{SCR}_{1}=1.2$ and $\mathrm{SCR}_{2}=2.5$; (ii) $\mathrm{SCR}_{1}=2.5$ and $\mathrm{SCR}_{2}=1.2$; (iii) $\mathrm{SCR}_{1}=\mathrm{SCR}_{2}=1.8$.

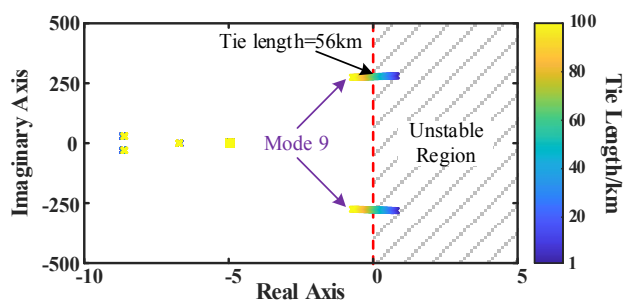

(a) $\mathrm{SCR}_{1}=1.2, \mathrm{SCR}_{2}=2.5$

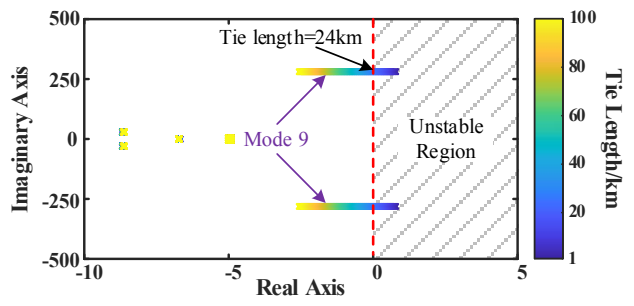

(b) $\mathrm{SCR}_{1}=2.5, \mathrm{SCR}_{2}=1.2$ 


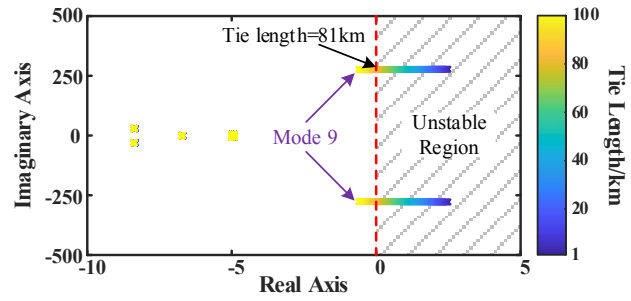

(c) $\mathrm{SCR}_{1}=\mathrm{SCR}_{2}=1.8$

Fig. 15. Root loci of system with tie line length varying.

Fig. 15(a)-(c) exhibit similar results, i.e., the decrease of the length of the tie line could cause the system instability, except for that the minimum acceptable length of the tie line is different. For scenario 1 in which $\mathrm{SCR}_{1}=1.2$ and $\mathrm{SCR}_{2}=2.5$, the minimum acceptable length of the tie line is $56 \mathrm{~km}$, while for scenario $2\left(\mathrm{SCR}_{1}=2.5, \mathrm{SCR}_{2}=1.2\right)$ and scenario $3\left(\mathrm{SCR}_{1}\right.$ $=\mathrm{SCR}_{2}=1.8$ ), the minimum acceptable length of the tie line is $24 \mathrm{~km}$ and $81 \mathrm{~km}$, respectively. It can be seen again that although scenario 1 and scenario 2 are arranged symmetrically, their minimum acceptable tie line lengths are different because $\mathrm{AC}$ grids 1 and 2 are connected to different types of converters.

To further study the impact of the proximity of the receiving $\mathrm{AC}$ grids on the system, the feasible region of SCR at different tie line lengths is illustrated in Fig. 16.

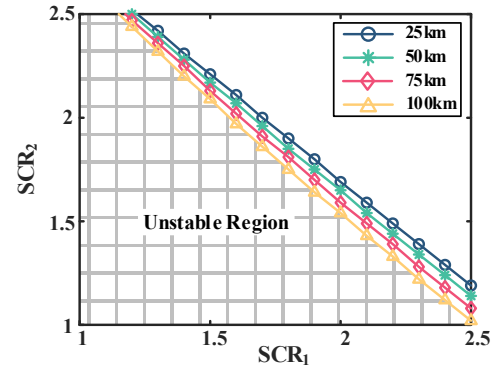

Fig. 16. Feasible region of SCR under different tie line length.

It can be seen in Fig. 16 that as the length of the tie line increases, the critical SCR line moves towards the lower left and the feasible region of SCR is enlarged. It indicates that the small-signal stability of the system is enhanced; namely, the system under the same SCR configuration may change from an unstable condition to a stable condition with the increase of the tie line length.

To estimate the interaction degree between LCC and MMC, the multi-infeed interaction factor (MIIF) proposed by CIGRE WG B4 is applied [30]. When the interaction is strong, MIIF is high, and vice versa. Fig. 17 shows the MIIF with the length of the tie line varying.

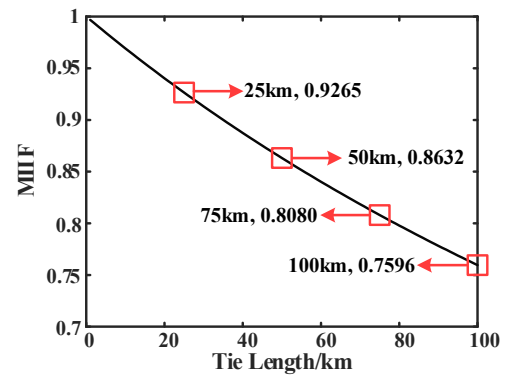

Fig. 17. MIIF with tie length varying

It can be observed in Fig. 17 that as the length of the tie line increases, MIIF decreases, which implies that the interaction between LCC and MMC weakens. According to the previous results, it is apparent that strong interaction between converters is more likely to cause a small-signal instability in the system. Thus, a longer electrical distance between PCCs is suggested when the HVDC link is fed into the receiving AC grids.

\section{SuPPlementary COUPLing Mitigation CONTROL}

As mentioned before, a temporary decline in the strength of the AC grid will occur, due to scheduled maintenance or occasional AC faults, which may lead the system to change to an unstable condition from the previous stable condition. Section V has shown that the decreased coupling between converters can help improve stability. Since it is impractical to increase the tie line length to attenuate the coupling between converters for a commissioned project, this paper proposes a supplementary coupling mitigation control (SCMC). It reduces the coupling between converters by virtually increasing the tie line length, and its schematic diagram is depicted in Fig. 18.

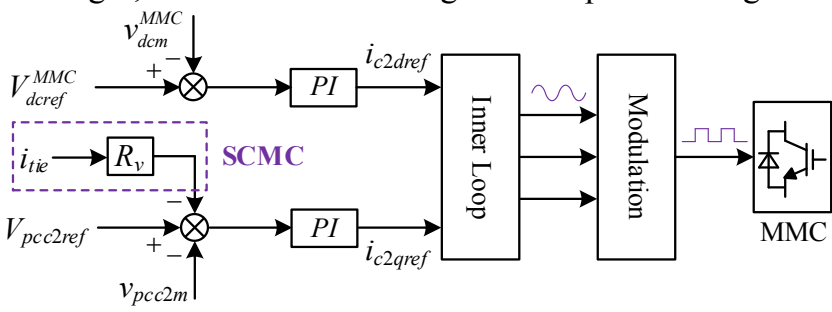

Fig. 18 Schematic diagram of supplementary coupling mitigation control.

In Fig. 18, SCMC introduces the product of the tie line current $i_{\text {tie }}$ and the virtual resistance $R_{v}$ into the outer AC voltage control loop of MMC to modify the AC voltage reference value, and to further virtually change the length of the tie line.

To investigate the impact of the virtual resistance $R_{v}$ on the small-signal stability of the system, the root loci of the system with $R_{v}$ varying are depicted in Fig. 19 (a)-(c), under the following three SCR configurations: (i) $\mathrm{SCR}_{1}=1$ and $\mathrm{SCR}_{2}=$ 2.5; (ii) $\mathrm{SCR}_{1}=2.5$ and $\mathrm{SCR}_{2}=1$; (iii) $\mathrm{SCR}_{1}=\mathrm{SCR}_{2}=1.8$. To better testify the effect of the supplementary control, a stronger coupling (tie length $=25 \mathrm{~km}$ ) is considered.

It can be seen in Fig. 19(a) that when $R_{v}=0$ pu (SCMC is disabled), the dominant mode of the system lies in the unstable region. With the increase of $R_{v}$, the dominant mode of the system moves towards the left and the system restores stability when $R_{v}>0.052 \mathrm{pu}$. In addition to the difference in the minimum acceptable $R_{v}$, similar results could also be observed in Fig. 19(b) and (c). Their minimum acceptable $R_{v}$ are 0.034 pu and $0.082 \mathrm{pu}$, respectively.

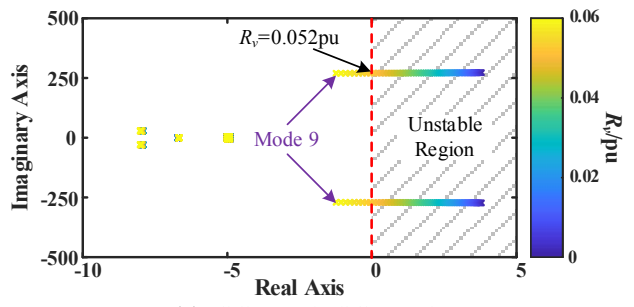

(a) $\mathrm{SCR}_{1}=1, \mathrm{SCR}_{2}=2.5$ 


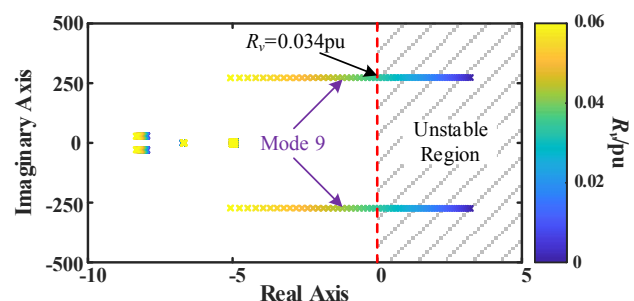

(b) $\mathrm{SCR}_{1}=2.5, \mathrm{SCR}_{2}=1$

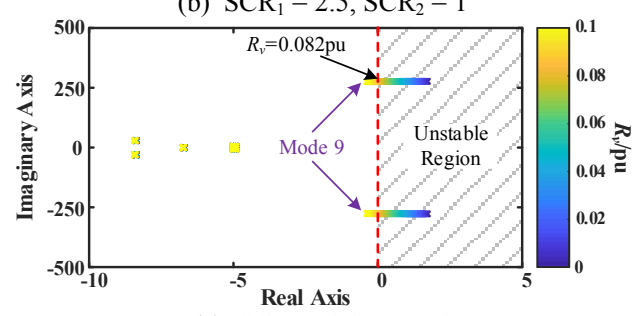

(c) $\mathrm{SCR}_{1}=\mathrm{SCR}_{2}=1.8$

Fig. 19. Root loci of system with $R_{v}$ varying (tie length $=25 \mathrm{~km}$ ).

The feasible region of SCR with $R_{v}$ varying is shown in Fig. 20. From Fig. 20, the increase of $R_{v}$ can expand the feasible region of SCR. It is noticeable that when $R_{v}=0.04 \mathrm{pu}$, the critical SCR line is no longer a straight line, but a convex curve.

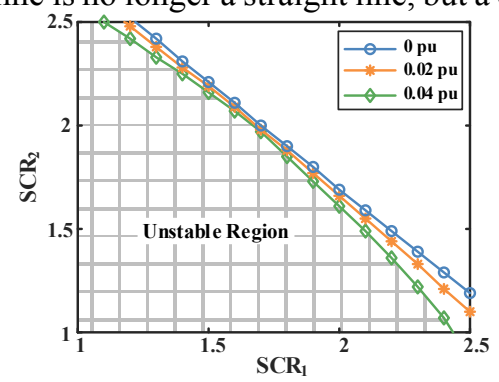

Fig. 20. Feasible region of SCR with $R_{v}$ varying (tie length $=25 \mathrm{~km}$ ).

Fig. 21(a)-(c) show the time-domain simulation results, which correspond to the unstable, critical stable and stable conditions of the system in Fig. 19(a), respectively. They verify the effectiveness of the supplementary coupling mitigation control. The value of the virtual resistance $R_{v}$ should be reasonably determined. On the one hand, if the value is too small, it will not provide enough damping; On the other hand, if the value is too high, the $\mathrm{AC}$ voltage of $\mathrm{PCC}_{2}$ may seriously deviate the rated value and affect the normal operation of the system.

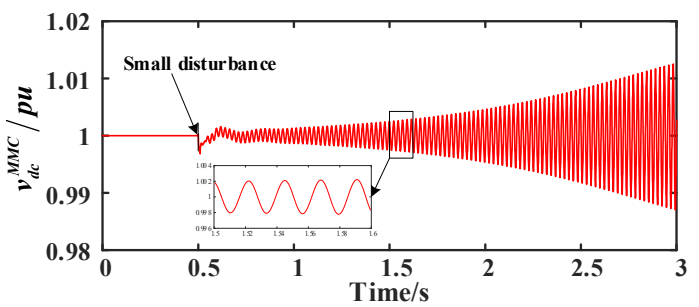

(a) Disabled $\left(R_{v}=0 \mathrm{pu}\right)$

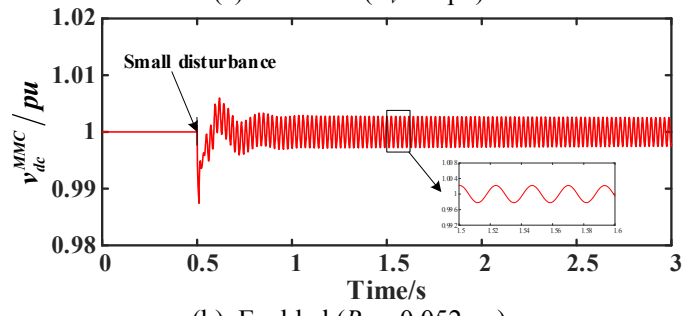

(b) Enabled $\left(R_{v}=0.052 \mathrm{pu}\right)$

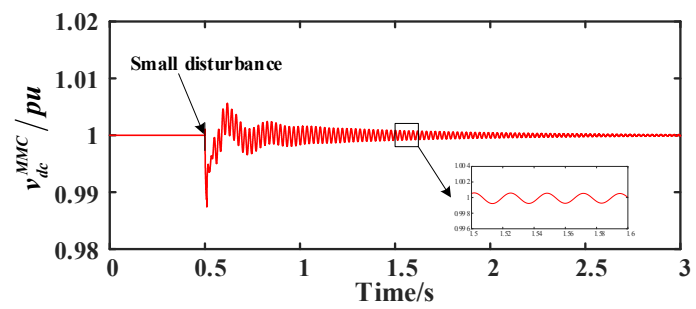

(c) Enabled $\left(R_{v}=0.06 \mathrm{pu}\right)$

Fig. 21. Verification of supplementary coupling mitigation control $\left(\mathrm{SCR}_{1}=1\right.$, $\mathrm{SCR}_{2}=2.5$, tie length $=25 \mathrm{~km}$ ).

\section{CONCLUSION}

A comprehensive small-signal model of the cascaded LCCMMC inverter based hybrid HVDC system is established and validated in this paper. The small-signal model is then used to analyze the impact of the strength and proximity of the receiving $\mathrm{AC}$ grids. The supplementary coupling mitigation control to improve the stability of the system under weak AC systems integration is also demonstrated by eigenvalue analysis and time-domain simulation.

The results indicate that the decrease of the strength of the receiving $\mathrm{AC}$ grids will result in system instability. The minimum acceptable SCRs of two receiving AC grids satisfy a linear constraint and $\mathrm{MMC}$ can tolerate a weaker $\mathrm{AC}$ grid integration than LCC. As two receiving AC grids are close, the increased coupling between converters will decline the smallsignal stability margin of the system, and vice versa. When the HVDC link is fed into the receiving AC grids, the strength of the $\mathrm{AC}$ grids should be in the stable zone and a longer tie line is preferable. The value of the virtual resistance should be set reasonably by practical requirement, and too high or small is inappropriate.

\section{APPENDIX A}

The internal dynamics of MMC, including the submodule capacitor voltage ripples $\left(v_{c p x 2}^{\Sigma}, v_{c p y 2}^{\Sigma}, v_{c p x}^{\Sigma}, v_{c p y}^{\Sigma}, v_{c p 0}^{\Sigma}\right)$ and the internal circulating current $\left(i_{\text {cirx } 2}, i_{\text {ciry2 } 2}\right)$, are described by the following equations:

$$
\begin{gathered}
\frac{d v_{c p x 2}^{\Sigma}}{d t}=2 \omega_{0} v_{c p y 2}^{\Sigma}+\frac{i_{c i r x 2}}{2 C_{a r m}}-\frac{m_{2 x 2} i_{d c 2}}{6 C_{a r m}}-\frac{m_{x} i_{c 2 x}}{8 C_{a r m}}+\frac{m_{y} i_{c 2 y}}{8 C_{a r m}} \\
\frac{d v_{c p y 2}^{\Sigma}}{d t}=-2 \omega_{0} v_{c p x 2}^{\Sigma}+\frac{i_{c i r y 2}}{2 C_{a r m}}-\frac{m_{2 y 2} i_{d c 2}}{6 C_{a r m}}-\frac{m_{y} i_{c 2 x}}{8 C_{a r m}}-\frac{m_{x} i_{c 2 y}}{8 C_{a r m}} \\
\frac{d v_{c p x}^{\Sigma}}{d t}=\omega_{0} v_{c p y}^{\Sigma}-\frac{m_{x} i_{c i r x 2}}{4 C_{a r m}}-\frac{m_{y} i_{c i r y 2}}{4 C_{a r m}}-\frac{m_{x} i_{d c 2}}{6 C_{a r m}}- \\
\frac{\left(m_{2 x 2}-2\right) i_{c 2 x}}{8 C_{a r m}}-\frac{m_{2 y 2} i_{c 2 y}}{8 C_{a r m}} \\
\frac{d v_{c p y}^{\Sigma}}{d t}=-\omega_{0} v_{c p x}^{\Sigma}+\frac{m_{y} i_{c i r x 2}}{4 C_{a r m}}-\frac{m_{x} i_{c i r y 2}}{4 C_{a r m}}-\frac{m_{y} i_{d c 2}}{6 C_{a r m}}- \\
\frac{m_{2 y 2} i_{c 2 x}}{8 C_{a r m}}+\frac{\left(m_{2 x 2}+2\right) i_{c 2 y}}{8 C_{a r m}} \\
\frac{m_{c p 0} i_{c i r x 2}}{d t}=\frac{m_{2 y 2} i_{c i r y 2}}{4 C_{a r m}}+\frac{i_{d c 2}}{6 C_{a r m}}-\frac{m_{x} i_{c 2 x}}{8 C_{a r m}}-\frac{m_{y} i_{c 2 y}}{8 C_{a r m}}
\end{gathered}
$$




$$
\begin{aligned}
\frac{d i_{c i x x 2}}{d t}= & -\frac{v_{c p x 2}^{\Sigma}}{2 L_{a r m}}+\frac{m_{x} v_{c p x}^{\Sigma}}{4 L_{a r m}}-\frac{m_{y} v_{c p y}^{\Sigma}}{4 L_{a r m}}+\frac{m_{2 x 2} v_{c p 0}^{\Sigma}}{2 L_{a r m}} \\
& -\frac{R_{a r m}}{L_{a r m}} i_{c i r x 2}+2 \omega_{0} i_{c i r y 2} \\
\frac{d i_{c i r y 2}}{d t}= & -\frac{v_{c p y 2}^{\Sigma}}{2 L_{a r m}}+\frac{m_{y} v_{c p x}^{\Sigma}}{4 L_{a r m}}+\frac{m_{x} v_{c p y}^{\Sigma}}{4 L_{a r m}}+\frac{m_{2 y 2} v_{c p 0}^{\Sigma}}{2 L_{a r m}} \\
& -2 \omega_{0} i_{c i r x 2}-\frac{R_{a r m}}{L_{a r m}} i_{c i r y 2}
\end{aligned}
$$

where $C_{a r m}=C_{s m} / N_{s m} . C_{s m}$ is the submodule capacitance. $N_{s m}$ is the number of submodules per arm.

\section{APPENDIX B}

The dynamic equations of PLL are as follows:

$$
\left\{\begin{array}{l}
\frac{d}{d t} x_{p l l}=k_{i p l l}\left(\theta_{p c c}-\theta_{p l l}\right) \\
\frac{d}{d t} \theta_{p l l}=x_{p l l}+k_{p p l l}\left(\theta_{p c c}-\theta_{p l l}\right)
\end{array}\right.
$$

where $k_{p p l l}$ and $k_{i p l l}$ are the proportional and integral gains of PLL, respectively; $x_{p l l}$ is the state variable of PLL; $\theta_{p c c}$ is the phase angle of PCC, and $\theta_{p c c}=\tan ^{-1}\left(v_{p c c y} / v_{p c c x}\right)$.

The dynamic of the controller of LCC inverter can be represented as:

$$
\left\{\begin{array}{l}
\frac{d}{d t} x_{i}=k_{i i}\left(v_{d c m}^{L C C i}-V_{d c r e f}^{L C C i}\right) \\
\beta_{i}=x_{i}+k_{p i}\left(v_{d c m}^{L C C i}-V_{d c r e f}^{L C C i}\right)-\left(\theta_{p c c 1}-\theta_{p l l 1}\right)
\end{array}\right.
$$

where $k_{p i}$ and $k_{i i}$ are the proportional and integral gains of the controller of LCC inverter, respectively; $x_{i}$ is the state variable of the controller of LCC inverter.

The dynamic behavior of the controller of LCC rectifier can be described:

$$
\left\{\begin{array}{l}
\frac{d}{d t} x_{r}=k_{i r}\left(I_{d c r e f}-i_{d c 1 m}\right) \\
\alpha_{r}=\pi-\left[x_{r}+k_{p r}\left(I_{d c r e f}-i_{d c 1 m}\right)\right]+\left(\theta_{p c c 3}-\theta_{p l l 3}\right)
\end{array}\right.
$$

where $k_{p r}$ and $k_{i r}$ are the proportional and integral gains of the controller of LCC rectifier, respectively; $x_{r}$ is the state variable of the controller of $\mathrm{LCC}$ rectifier.

The dynamic equations of the outer voltage/power control loop of MMC are as follows:

$$
\begin{gathered}
\left\{\begin{array}{l}
\frac{d}{d t} x_{o d}=k_{i o d}\left(v_{d c m}^{M M C}-V_{d c r e f}^{M M C}\right) \\
i_{c 2 d r e f}=x_{o d}+k_{p o d}\left(v_{d c m}^{M M C}-V_{d c r e f}^{M M C}\right)
\end{array}\right. \\
\left\{\begin{array}{l}
\frac{d}{d t} x_{o q}=k_{i o q}\left(v_{p c c 2 m}-V_{p c c 2 r e f}\right) \\
i_{c 2 q r e f}=x_{o q}+k_{p o q}\left(v_{p c c 2 m}-V_{p c c 2 r e f}\right)
\end{array}\right.
\end{gathered}
$$

where $k_{p o d} / k_{p o q}$ and $k_{i o d} / k_{i o q}$ are the proportional and integral gains of $d$-axis/ $q$-axis outer loop, respectively; $x_{o d} / x_{o q}$ is the state variable of $d$-axis $/ q$-axis outer loop.

The dynamic equations of inter $\mathrm{AC}$ current control loop of $\mathrm{MMC}$ are as follows:

$$
\begin{aligned}
& \left\{\begin{array}{l}
\frac{d}{d t} x_{i d}=k_{i d d}\left(i_{c 2 d r e f}-i_{c 2 d m}\right) \\
m_{d}=v_{p c c 2 d m}+x_{i d}+k_{p i d}\left(i_{c 2 d r e f}-i_{c 2 d m}\right)-\omega_{2} L_{e q} i_{c 2 q m}
\end{array}\right. \\
& \left\{\begin{array}{l}
\frac{d}{d t} x_{i q}=k_{i i q}\left(i_{c 2 q r e f}-i_{c 2 q m}\right) \\
m_{q}=v_{p c c 2 q m}+x_{i q}+k_{p i q}\left(i_{c 2 q r e f}-i_{c 2 q m}\right)+\omega_{2} L_{e q} i_{c 2 d m}
\end{array}\right.
\end{aligned}
$$

where $k_{\text {pid }} / k_{\text {piq }}$ and $k_{\text {iid }} / k_{\text {iiq }}$ are the proportional and integral gains of $d$-axis/ $q$-axis inner loop, respectively; $x_{i d} / x_{i q}$ is the state variable of $d$-axis $/ q$-axis inner loop.

The dynamic of the circulating current suppression control of MMC can be represented as:

$$
\begin{aligned}
& \left\{\begin{array}{l}
\frac{d}{d t} x_{c d}=k_{i c d}\left(I_{\text {cird } 2 \text { ref }}-i_{\text {cird } 2 m}\right) \\
m_{d 2}=-x_{c d}-k_{p c d}\left(I_{\text {cird } 2 \text { ref }}-i_{\text {cird } 2 m}\right)-2 \omega_{2} L_{\text {arm }} i_{\text {cird } 2 m}
\end{array}\right. \\
& \left\{\begin{array}{l}
\frac{d}{d t} x_{c q}=k_{i c q}\left(I_{\text {cir } 2 \text { ref }}-i_{\text {cirq } 2 m}\right) \\
m_{q 2}=-x_{c q}-k_{p c q}\left(I_{\text {cirq } 2 \text { ref }}-i_{\text {cirq } 2 m}\right)+2 \omega_{2} L_{\text {arm }} i_{\text {cirr } 2 m} 2 m
\end{array}\right.
\end{aligned}
$$

where $k_{p c d} / k_{p c q}$ and $k_{i c d} / k_{i c q}$ are the proportional and integral gains of $d$-axis $/ q$-axis of circulating current suppression control, respectively; $x_{c d} / x_{c q}$ is the state variable of $d$-axis $/ q$-axis of circulating current suppression control.

All measured values are obtained through the first-order feedback filter. The dynamic equation of the first-order feedback filter can be expressed as:

$$
\frac{d}{d t} y=\frac{G}{T} x-\frac{1}{T} y
$$

where $x$ and $y$ are the input and output of first-order feedback filter, respectively; $G$ and $T$ are the gain and time constant of first-order feedback filter, respectively.

\section{APPENDIX C}

TABLE C I AC FILTER \& VAR COMPENSATION PARAMETERS

\begin{tabular}{l|l|l}
\hline \hline \multirow{2}{*}{ Parameters } & \multicolumn{2}{|c}{ Values } \\
\cline { 2 - 3 } & \multicolumn{1}{|c}{ Rectifier-side } & \multicolumn{1}{|c}{ Inverter-side } \\
\hline$C_{f}$ & $2.3002 \mu \mathrm{F}$ & $1.1221 \mu \mathrm{F}$ \\
\hline$C_{h p}$ & $4.6004 \mu \mathrm{F}$ & $2.2441 \mu \mathrm{F}$ \\
\hline$L_{h p}$ & $0.0056 \mathrm{H}$ & $0.0115 \mathrm{H}$ \\
\hline$R_{h p}$ & $49.4228 \Omega$ & $101.317 \Omega$ \\
\hline$C_{1}$ & $4.6004 \mu \mathrm{F}$ & $2.2441 \mu \mathrm{F}$ \\
\hline$L_{1}$ & $0.0154 \mathrm{H}$ & $0.0316 \mathrm{H}$ \\
\hline$C_{2}$ & $164.46 \mu \mathrm{F}$ & $80.2264 \mu \mathrm{F}$ \\
\hline$L_{2}$ & $0.4308 \mathrm{mH}$ & $0.8832 \mathrm{mH}$ \\
\hline$R_{2}$ & $0.0162 \Omega$ & $0.0332 \Omega$ \\
\hline \hline
\end{tabular}

TABLE C II FEEDBACK Filter PARAMETERS

\begin{tabular}{l|l|l}
\hline \hline \multicolumn{2}{c|}{ Parameters } & \multicolumn{1}{c}{ Values } \\
\hline$v_{d c}^{L C C i}$ filter & $G_{v d i}, T_{v d i}$ & $1,10 \mathrm{~ms}$ \\
\hline$i_{d c 1}$ filter & $G_{i d r}, T_{i d r}$ & $1,20 \mathrm{~ms}$ \\
\hline$v_{d c}^{M M C}$ filter & $G_{v d c}, T_{v d c}$ & $1,10 \mathrm{~ms}$ \\
\hline$v_{p c c 2}$ filter & $G_{v}, T_{v}$ & $1,10 \mathrm{~ms}$ \\
\hline$v_{p c c 2 d}$ filter & $G_{v d}, T_{v d}$ & $1,2 \mathrm{~ms}$ \\
\hline$v_{p c c 2 q}$ filter & $G_{v q}, T_{v q}$ & $1,2 \mathrm{~ms}$ \\
\hline$i_{c 2 d}$ filter & $G_{i d}, T_{i d}$ & $1,1 \mathrm{~ms}$ \\
\hline$i_{c 2 q}$ filter & $G_{i q}, T_{i q}$ & $1,1 \mathrm{~ms}$ \\
\hline \hline
\end{tabular}




\begin{tabular}{l|l|l}
\hline \hline$i_{\text {cird } 2}$ filter & $G_{i c d}, T_{i c d}$ & $1,2 \mathrm{~ms}$ \\
\hline$i_{\text {cirq } 2}$ filter & $G_{\text {icq }}, T_{i c q}$ & $1,2 \mathrm{~ms}$ \\
\hline \hline
\end{tabular}

\section{REFERENCES}

[1] Z. Liu, J. Yu, X. Guo and et al., "Survey of technologies of line commutated converter based high voltage direct current transmission in China," CSEE J. Power Energy Syst., vol. 1, no. 2, pp. 1-8, Jun. 2015.

[2] B. Ni, W. Xiang, M. Zhou and et al., "An adaptive fault current limiting control for MMC and its application in DC grid," IEEE Trans. Power Del., early access, to be published.

[3] H. Rao, Y. Zhou, C. Zou and et al., "Design aspects of the hybrid HVDC system," CSEE J. Power Energy Syst., early access, to be published.

[4] F. Zhang, H. Xin, D. Wu and et al, "Assessing strength of multi-infeed LCC-HVDC systems using generalized short-circuit ratio," IEEE Trans. Power Syst., vol. 34, no. 1, pp. 467-480, Jan. 2019.

[5] W. Xiang, S. Yang, G. P. Adam and et al., "DC Fault Protection Algorithms of MMC HVDC Grids: Fault analysis, Methodologies, Experimental Validations and Future Trends," IEEE Tran. Power Electron., early access, to be published.

[6] W. Xiang, S. Yang, L. Xu and et al., "A Transient Voltage-Based DC Fault Line Protection Scheme for MMC-Based DC Grid Embedding DC Breakers," IEEE Trans Power Del., vol. 34, no. 1, pp. 334-345, Feb. 2019.

[7] W. Xiang, R. Yang, C. Lin and et al., "A cascaded converter interfacing long-distance HVDC and back-to-back HVDC systems," IEEE J. Emerg. Sel. Topics Power Electron., vol. 8, no. 4, pp. 4109-4121, Dec. 2020.

[8] G. Andersson and M. Hyttinen, "Skagerrak - The next generation HVDC and power electronic technology system development and economics, CIGRE Symposium Lund - 2015, Lund, Sweden, 2015, pp. $1-9$.

[9] Y. Huang, W. Huang, M. Ling and T. Liu, "Steady-state control strategy of multi-terminal hybrid UHVDC," 2017 19th European Conference on Power Electronics and Applications (EPE'17 ECCE Europe), Warsaw, Poland, 2017, pp. 1-10.

[10] B. Chang, J. Zhou, C. Lin and et al., "Hybrid series-connected HVDC system faults analysis," 2019 4th IEEE Workshop on the Electronic Grid (eGRID), Xiamen, China, 2019, pp. 1-6.

[11] K. Sun, H. Xiao, J. Pan and Y. Liu, "A station-hybrid HVDC system structure and control strategies for cross-seam power transmission," IEEE Trans. Power Syst., early access, to be published.

[12] H. Saad, Y. Fillion, S. Deschanvres, Y. Vernay and S. Dennetière, "On resonances and harmonics in HVDC-MMC station connected to AC grid," IEEE Trans. Power Del., vol. 32, no. 3, pp. 1565-1573, Jun. 2017.

[13] X. Lu, W. Xiang, W. Lin and J. Wen, "Comparative study of small-signal stability under weak AC system integration for different VSCs," IEEE J. Emerg. Sel. Topics Power Electron., early access, to be published.

[14] J. Z. Zhou, H. Ding, S. Fan and et al., "Impact of short-circuit ratio and phase-locked-loop parameters on the small-signal behavior of a VSCHVDC converter," IEEE Trans. Power Del., vol. 29, no. 5, pp. 22872296, Oct. 2014

[15] D. Jovcic, N. Pahalawaththa and M. Zavahir, "Small signal analysis of HVDC-HVAC interactions," IEEE Trans. Power Del., vol. 14, no. 2, pp. 525-530, Apr. 1999.

[16] C. Osauskas and A. Wood, "Small-Signal dynamic modeling of HVDC systems," IEEE Trans. Power Del., vol. 18, no. 1, pp. 220-225, Jan. 2003.

[17] M. Daryabak, S. Filizadeh, J. Jatskevich and et al., "Modeling of LCCHVDC systems using dynamic phasors," IEEE Trans. Power Del., vol. 29, no. 4, pp. 1989-1998, Aug. 2014.

[18] J. Lu, X. Yuan, J. Hu and et al., "Motion equation modeling of LCCHVDC stations for analyzing DC and AC network interactions," IEEE Trans. Power Del., vol. 35, no. 3, pp. 1563-1574, Jun. 2020.

[19] A. Jamshidifar and D. Jovcic, "Small-Signal dynamic DQ model of modular multilevel converter for system studies," IEEE Trans. Power Del., vol. 31, no. 1, pp. 191-199, Feb. 2016.

[20] T. Li, A. M. Gole and C. Zhao, "Harmonic instability in MMC-HVDC converters resulting from internal dynamics," IEEE Trans. Power Del., vol. 31, no. 4, pp. 1738-1747, Aug. 2016.

[21] X. Lu, W. Xiang, W. Lin, and J. Wen, " Small-Signal modeling of MMC based DC grid and analysis of the impact of DC reactors on the smallsignal stability," Int. J. Electr. Power Energy Syst., vol. 101, pp. 25-37, 2018.

[22] G. Bergna-Diaz, J. A. Suul and S. D'Arco, "Energy-Based state-space representation of modular multilevel converters with a constant equilibrium point in steady-state operation," IEEE Trans. Power Electron., vol. 33, no. 6, pp. 4832-4851, Jun. 2018.

[23] G. Bergna-Diaz, J. Freytes, X. Guillaud and et al., "Generalized voltagebased state-space modeling of modular multilevel converters with constant equilibrium in steady state," IEEE J. Emerg. Sel. Topics Power Electron., vol. 6, no. 2, pp. 707-725, Jun. 2018.

[24] X. Lu, W. Xiang, W. Lin and J. Wen, "Analysis of wide-band oscillation of hybrid MMC interfacing weak AC power system," IEEE J. Emerg. Sel. Topics Power Electron., early access, to be published.

[25] O. Kotb, M. Ghandhari, R. Eriksson and V. K. Sood, "On small signal stability of an AC/DC power system with a hybrid MTDC network," Electr. Power Syst. Res., vol. 136, pp. 79-88, 2016.

[26] C. Guo, Z. Yin, C. Zhao and R. Iravani, " Small-signal dynamics of hybrid LCC-VSC HVDC systems," Int. J. Electr. Power Energy Syst., vol. 98, pp. 362-372, 2018.

[27] C. Guo, A. Zheng, Z. Yin and C. Zhao, "Small-Signal stability of hybrid multi-terminal HVDC system," Int. J. Electr. Power Energy Syst., vol. 109, pp. 434-443, 2019.

[28] P. Kunder, Power system stability and control. New York, NY, USA: McGraw-Hill, 1994

[29] W. Hammer, "Dynamic Modeling of Line and Capacitor Commutated Converters for HVDC Power Transmission," Ph.D., Dept. Elect. Eng., Swiss Federal Inst. Technol., Zurich, Switzerland, 2003.

[30] B. Davies et al., Systems with multiple dc infeed, CIGRE Working Group B4.41, Paris, France, pp. 12-14, Dec. 2008.

\section{BIOGRAPHIES}

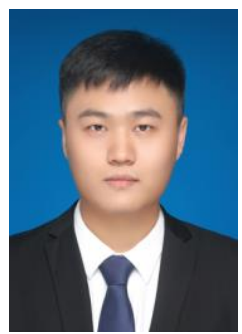

Yongjie He received his B.Eng. degree in electrical engineering from Huazhong University of Science and Technology (HUST), Wuhan, China, in 2018. He is currently working toward the Ph.D. degree at HUST. His research interests include modelling and stability analysis of LCC-HVDC, MMC-HVDC and dc grids.

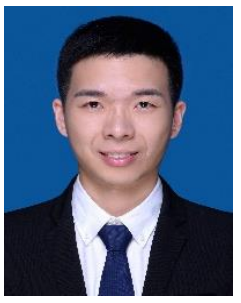

Wang Xiang (S'16-M'17) received his B.Eng. and PhD degrees both in electrical engineering from Huazhong University of Science and Technology (HUST), China in 2012 and 2017, respectively. He was a visiting student at the University of Aberdeen and the University of Strathclyde in 2014 and 2016 respectively. Currently, he is a research associate with the University of Strathclyde since 2018. His main research interests include MMC-HVDC, high power dc/dc converters and de grids.

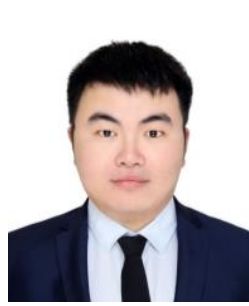

Binye Ni received his B.Eng. degree in electrical engineering from Huazhong University of Science and Technology (HUST), Wuhan, China, in 2017. He is currently working toward the Ph.D. degree at HUST. His research interests include HVDC control and protection, dc circuit breaker and dc grids.

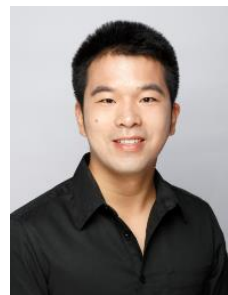

Xiaojun Lu received his B.Eng. and $\mathrm{PhD}$ degrees both in electrical engineering from Huazhong University of Science and Technology (HUST), China in 2013 and 2018, respectively. He was a postdoctor with HUST from 2018 to 2020. He joined Changjiang Institute of Survey, Planning, Design and Research Co. Ltd. (CISPDR) from November 2020. Currently, he is a senior engineer with CISPDR. His main research interests include modeling and stability analysis of MMC-HVDC and dc grids. 
This paper is a post-print of a paper submitted to and accepted for publication in IEEE Transaction on Power Delivery and is subject to Institution of Electrical and Electronic Engineering Copyright. The copy of record is available at IEEE Xplore Digital Library

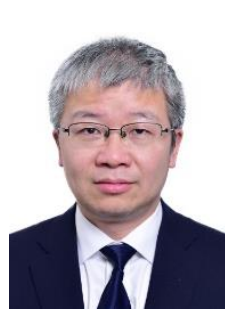

Jinyu Wen (M'10) received his B.Eng. and Ph.D. degrees all in electrical engineering from Huazhong University of Science and Technology (HUST), Wuhan, China, in 1992 and 1998, respectively. He was a visiting student from 1996 to 1997 and a research fellow from 2002 to 2003 all at the University of Liverpool, UK, and a senior visiting researcher at the University of Texas at Arlington, USA in 2010. From 1998 to 2002 he was a director engineer in XJ Electric Co. Ltd. in China. In 2003 he joined the HUST and now is a Professor at HUST. His current research interests include renewable energy integration, energy storage application, DC grid, and power system operation and control. 